\title{
A Review of High-Energy X-Ray Diffraction from Glasses and Liquids
}

\author{
C. J. Benmore \\ Department of Physics, Arizona State University, Tempe, AZ 85287-1604, USA \\ Correspondence should be addressed to C. J. Benmore, Chris.Benmore@asu.edu
}

Received 26 August 2012; Accepted 14 October 2012

Academic Editors: M. Leoni, A. O. Neto, and J. Provis

Copyright ( $\odot 2012$ C. J. Benmore. This is an open access article distributed under the Creative Commons Attribution License, which permits unrestricted use, distribution, and reproduction in any medium, provided the original work is properly cited.

This paper summarizes the scientific trends associated with the rapid development of the technique of high-energy X-ray diffraction over the past decade pertaining to the field of liquids, glasses, and amorphous materials. The measurement of highquality X-ray structure factors out to large momentum transfers leads to high-resolution pair distribution functions which can be directly compared to theory or combined with data from other experimental techniques. The advantages of combining highly penetrating radiation with low angle scattering are outlined together with the data analysis procedure and formalism. Also included are advances in high-energy synchrotron beamline instrumentation, sample environment equipment, and an overview of the role of simulation and modeling for interpreting data from disordered materials. Several examples of recent trends in glass and liquid research are described. Finally, directions for future research are considered within the context of past and current developments in the field.

\section{Introduction}

X-ray diffraction studies have long been used to obtain information on the short and intermediate range structure of glasses, since the pioneering work of Warren and coworkers in the 1930's [1-3]. This is still the case, although the measurement accuracy, data analysis procedure, and sophistication of the modeling techniques today are much more rigorous. The work of Narten and colleagues in the 1970's had a large impact on the development of data analysis techniques associated with the $\mathrm{X}$-ray pair distribution function method, using conventional X-ray sources mainly to study the structure of molecular liquids, for example, $[4,5]$. Around the same time, Leadbetter and Wright combined both neutron and X-ray diffraction to study the structure of network glasses $[6,7]$. However the main use of the pair distribution function technique in the field of glasses and liquids centered on neutron diffraction which has been described extensively by Wright [8-10] and others. The high-energy X-ray technique (loosely defined as energies $>60 \mathrm{keV}$ ) is the latest generation of this popular method of determining the structure of disordered materials and has its origins with the seminal work of Egelstaff and Root in the 1980's who used $\gamma$-ray diffraction to obtain liquid structure factors $[11,12]$. The breakthrough however came in the mid-90's by Neuefeind and Poulsen [13-15], when they adapted this technique to synchrotron radiation using $100 \mathrm{keV} \mathrm{X}$-rays. The triple axis high-energy X-ray diffractometer, BW5, they used for these measurements was built based on the design of the world's best neutron diffractometer at the time, D4C at the Institute Laue Langevin in France [13]. The high energy X-ray pair distribution function (PDF) technique has spread in the last decade and current synchrotron beamlines that routinely perform measurements on glasses include: SPring-8, Japan (BL04B2) [16, 17], HASYLAB [18], Germany (BW5), European Synchrotron Radiation Facility, France (ID15B), and several beamlines at the Advanced Photon Source, USA; 1-ID (stress/strain, high pressure), 11-ID-B (time resolved, chemical reactions), 11-ID-C [19] (liquid, glass, levitation). In the conference summary of the 10th International conference on the Structure of Non-Crystalline Materials in 2006, X-ray diffraction was identified as the main structural technique used by the participants.

There are two main advantages over conventional Xray diffraction techniques when hard X-rays of $\sim 100 \mathrm{keV}$ 


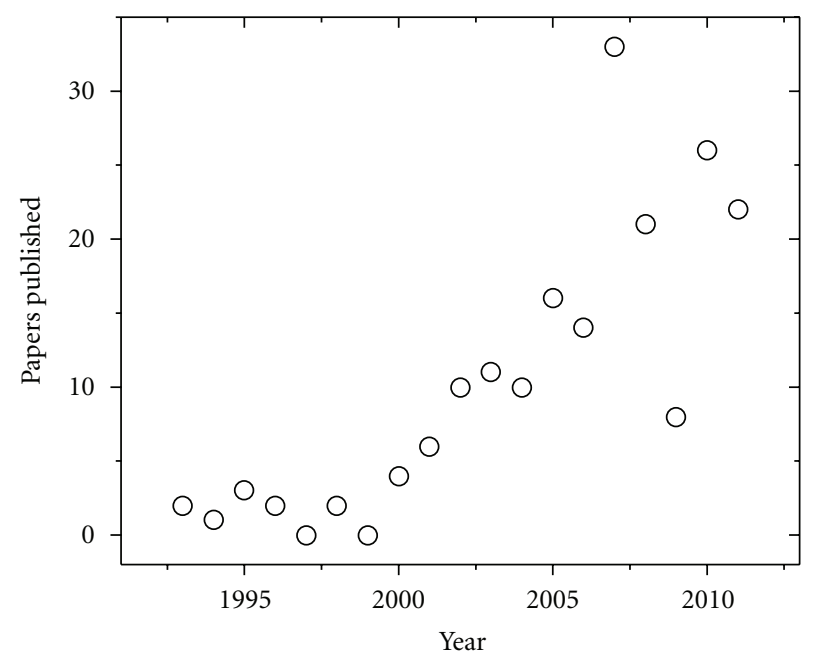

(a)

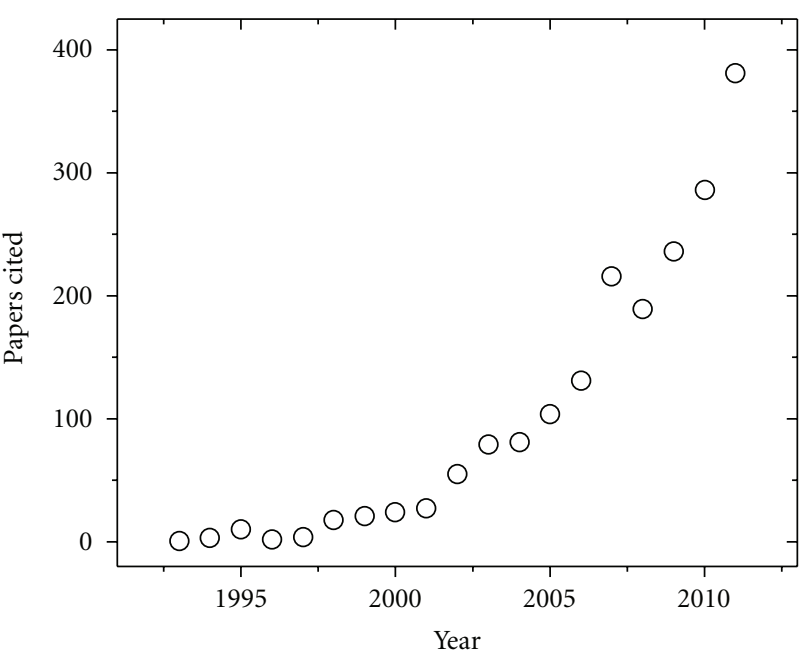

(b)

FIGURE 1: Plots showing the number of papers published per year and their citations from a Thomson Reuters Web of Knowledge database search using the key words "high energy X-ray diffraction" and "liquid" or "glass" cross-linked with several of the most prolific authors in the field. These articles were cited 1939 times by 1539 articles (excluding self-citations) with an average of 9.78 citations per item.

are used in experiments on amorphous materials: (i) the structure factors can be measured out to much higher momentum transfers, $Q>20 \AA^{-1}$ at smaller scattering angles (in $2 \theta^{\circ}$ ), leading to higher real space resolution, and (ii) attenuation and multiple scattering effects are negligible for small samples that is, typically $\sim 1 \mathrm{~mm}^{3}$ [13]. This is because the photo-electric absorption decreases as $\sim \mathrm{E}^{-3}$ and scattering typically becomes the dominant process, under conditions similar to that of a transmission neutron diffraction experiment. High energy X-ray diffraction is very much a sister technique to neutron diffraction, and as for all glass studies, whenever possible should be combined with other structural probes to maximize the information obtained. Limitations of the technique include that it is not element specific (like EXAFs) and therefore information on low dopant ions $(<1 \%)$ cannot be obtained. Fluorescence energies of elements in the sample should also be avoided if possible. One of the strengths of high energy diffraction data lies in its ability to provide a rigorous test of atomistic models from computer simulation such as molecular dynamics or density functional theory. It is also often used as a model constraint in inverse computer simulation techniques, such as Reverse Monte Carlo and Empirical Potential Structure Refinement. Some current directions of high energy X-ray synchrotron radiation in glass research include high pressure studies, high and low temperature experiments combined with containerless levitation techniques, and time resolved structural measurements around the glass transition.

To my knowledge there have been three reviews on high energy photon scattering specifically aimed at investigations into the structure of liquids and glasses. The first two were by Dr. J. Neuefeind in 2002 [20] and Professor P. A. Egelstaff in 2003 [21] shortly after high energy X-ray diffraction at third generation synchrotrons was born and these were followed by Dr. S. Kohara et al. review in 2007 [22]. During this time and since, the field has grown rapidly driven by advances in instrumentation and detectors at synchrotron sources, as illustrated in Figure 1. Here I attempt to update and rationalize these changes in the context of other current experimental and modeling methods. This paper is from my own perspective working for the past two decades in the field of liquids and glasses, and mainly describes the developments on sectors 1-ID and 11-ID-C at the Advanced Photon Source near Chicago, USA. This paper is by no means meant to be comprehensive and I apologize for those contributions to the field I have inadvertently omitted.

\section{2. $\gamma$-Ray Diffraction}

Knowing the atomic structure of a material is the starting point for explaining many macroscopic phenomena, unusual properties, or behavior. The ability to probe the bulk local and intermediate range structure of disordered materials is a powerful tool, yet for many materials science problems, more penetration is required than can be provided by conventional $\mathrm{X}$-ray instrumentation. The idea of high energy (low wavelength) radiation combined with low-angle detection came from developments in $\gamma$-ray scattering, the precursor to high energy X-ray diffraction. In particular, Egelstaff and Root designed and built a $\gamma$-ray diffractometer at the university of Guelph in Canada expressly built to measure liquid Xray structure factors [12]. A very stable $60 \mathrm{keV}$, Americium241 source was rotated in an arc around the sample with the heavier detector at a fixed position, see Figure 2. The limiting factors associated with these experiments were the low-flux, as experiments would typically take months to complete, which was compensated for by a large sample size leading to poor resolution at low angles and significant geometric, attenuation, and multiple scattering effects. 


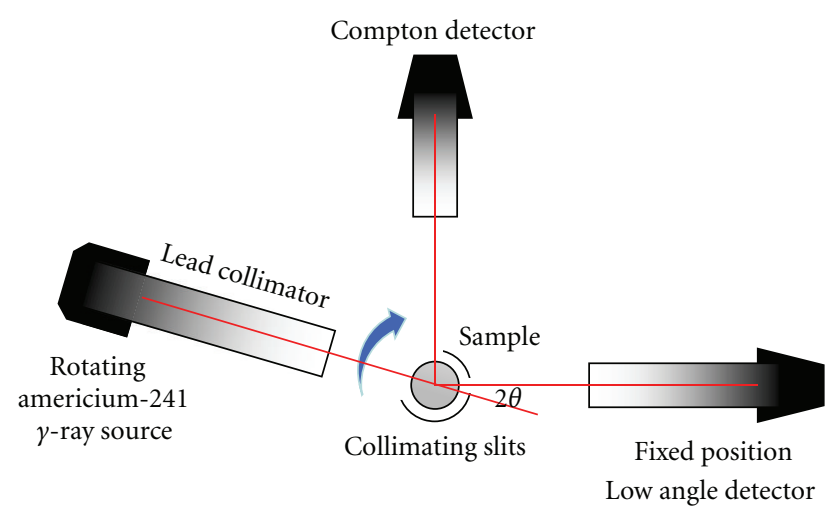

Figure 2: A schematic of the $60 \mathrm{keV} \gamma$-ray diffractometer built at the University of Guelph, Canada.

\section{High Energy X-Ray Instrumentation}

In the past, spallation neutron diffraction measurements have played an important role in elucidating the bulk structure of materials over a large range of scattering vector $Q$, covering low scattering angles and short wavelengths, but these experiments require comparatively lengthy counting times and large samples [23]. The use of "neutron-like" photons for diffraction studies at synchrotrons uses ca. $100 \mathrm{keV}$ photons to compress a wide Q-range into a small angular cone in the forward scattering direction, providing high real space resolution at low- $r$ values comparable to the best neutron sources. For example, the high energy Xray diffractometer 11-ID-C at the Advanced Photon Source was originally designed and built by Rütt and coworkers at the Basic Energy Sciences Synchrotron Radiation Center (BESSRC) in 2001 [19]. It was designed as a triple axis machine using an elliptical multipole wiggler. In 2007 the wiggler was replaced by two in-line undulators in a tandem configuration, one full length undulator A (downstream) and a full length high energy undulator with a period length of $2.3 \mathrm{~cm}$, providing simultaneous high brilliance flux to all three 11-ID stations (B, C, and D). The undulator $\mathrm{A}$ is limited to a minimum gap equivalent to $\mathrm{k}=2.11$ (minimum energy of $4.5 \mathrm{KeV}$ ) and the high energy undulator is used at fixed closed gap of $10.5 \mathrm{~cm}$. During a 2010 upgrade the 11-ID-C energy remained fixed at $115 \mathrm{keV}$ using a Laue $\mathrm{Si}(311)$ crystal reflection at 1.8 degrees, providing a highly penetrating beam and allowing a wide coverage of reciprocal space over a small angular scattering range. The flux is typically $10^{11}$ photons/sec using a beam size of $1 \mathrm{~mm} \times 1 \mathrm{~mm}$. In 2010, the end station was redesigned to take advantage of the advances in detector technology and rebuilt around a large moveable flat-plate area detector, see Figure 3. The open design, heavy duty sample stage, and extensive range of detector motion on 11-ID-C distinguishes it from beamlines performing similar measurements at other synchrotrons, such as BL04B2 and BL08W at SPring-8 [17] and ID-15B at ESRF. The use of short wavelength $\mathrm{X}$-rays are well suited to experiments that require bulky sample environments and much of the science program at beamline 11-ID-C revolves around studying the structure of phase transitions or materials characterization at nonambient conditions.

\section{Data Analysis and Corrections}

In the data analysis procedure we can consider three different origins of effects which can affect the accuracy of the extracted X-ray static structure factor [16, 24]: (i) effects related to the source for example, polarization, energy resolution, and relativistic effects; (ii) sample and environmental effects for example, container, attenuation, multiple scattering, florescence and (iii) detector effects, for example, geometrical arrangements, oblique incidence, detector efficiency, flat field, dark currents. Many of these have been covered in the literature and can be found here: $[16,24-26]$. These corrections and the order they are applied must be considered together with the removal of the background scattering (air or vacuum plus any windows) and the composition dependent Compton scattering. Removal of the "self scattering" (Compton plus X-ray form factor) allows the extraction of a pseudo-nuclear total X-ray structure factor, $S(Q)$ to be obtained. Provided a wide range of reciprocal space is covered this function can be Fourier transformed into real space to provide an average probability function of all the atomic positions in the material called the radial or pair distribution function $G_{X}(r)$ [1]. The $G_{X}(r)$ function can be used to extract bond distances, local coordination numbers, average bond angles, and provide a rigorous test of structural models. In addition, the first sharp diffraction peak at position $Q_{1}$ in the X-ray (or neutron) diffraction patterns is associated with the existence of intermediate or medium range order in glass with a periodicity of $2 \pi / Q_{1}$ (although its origin is still controversial). Medium range order has been defined as covering the region $\sim 5-10 \AA$, although longer "extended chemical ordering" up to $40 \AA$ has also been found in network glasses.

The sample dependent absorption corrections to the scattered X-ray intensity $I_{X}(Q)$ from a liquid or glass can be reliably applied using the method of Paalman and Pings [27], by independently measuring the sample scattering in a vessel $I_{0}^{\mathrm{SV}}$, the empty vessel $I_{0}^{V}$ and the background $B$,

$$
I_{X}(Q)=K\left(\frac{I_{0}^{\mathrm{SV}}-B}{A_{S, \mathrm{SV}}}-\frac{A_{V, \mathrm{SV}}\left(I_{0}^{V}-B\right)}{A_{S, \mathrm{SV}} A_{V, V}}\right)-\left\langle f^{2}(Q)\right\rangle M_{\mathrm{SV}},
$$

where the coefficient $A_{S, S V}$ represents the attenuation of the sample in the presence of the sample plus vessel, $A_{V, \mathrm{SV}}$ the attenuation of the vessel in the presence of the sample plus vessel, and $A_{V, V}$ the presence of the vessel in the presence of the vessel. The average scattering is given by

$$
\left\langle f^{2}(Q)\right\rangle=\left[\sum_{i, J=1}^{n} c_{i} f_{i}(Q)\right]^{2} .
$$

However, for thin samples with few electrons the ratio of multiple to single scattering $[28,29]$ of the sample in the vessel $M_{\mathrm{SV}}$ is negligible, so the second term in (1) can often 


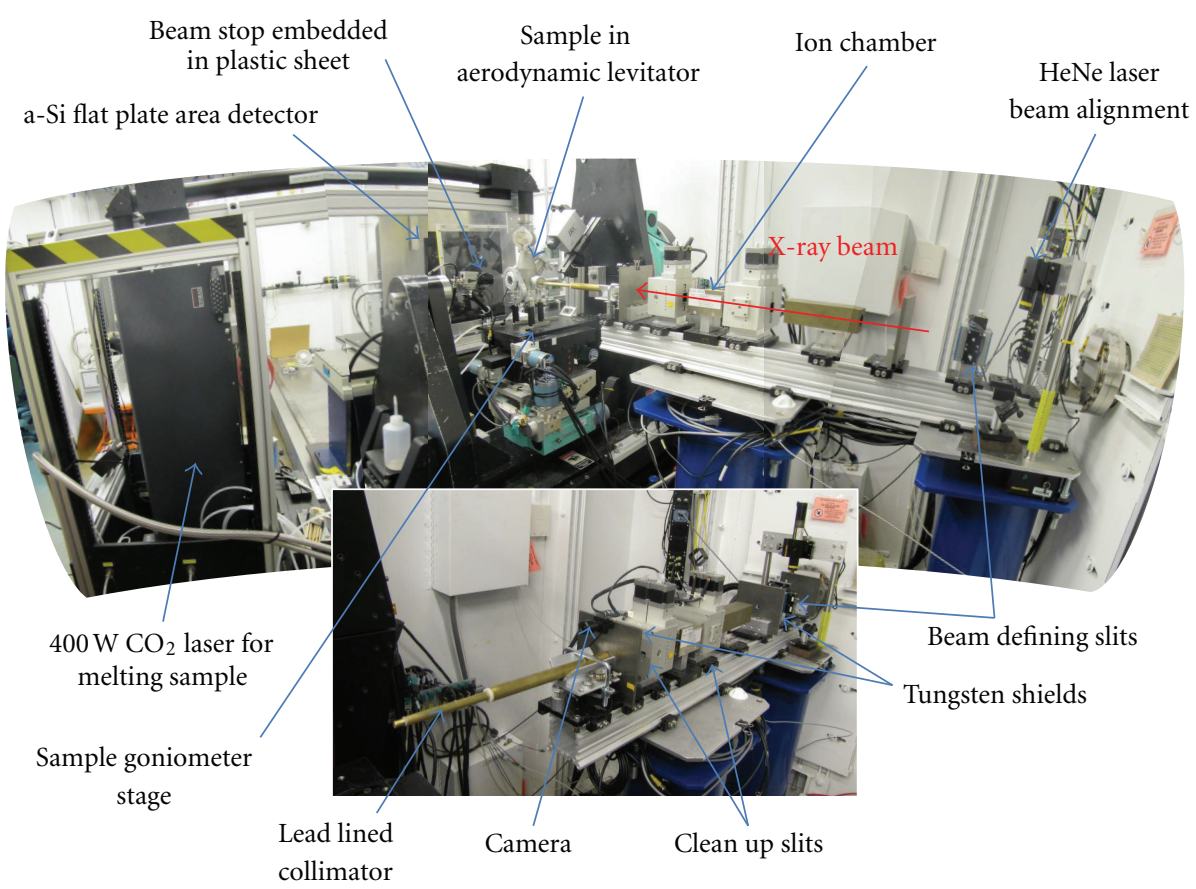

Figure 3: The high energy X-ray diffractometer 11-ID-C at the Advanced Photon Source with an aerodynamic levitator system installed.

be discarded. $K$ is the normalization factor [30] required to formalize $I_{X}(Q)$ to the number of electrons (plus any residual self-scattering, see (2) below) such that $S_{X}(Q)$ oscillates about unity at high $Q$ values. For homogeneous liquids the normalized $I_{X}(Q)$ tends to the isothermal compressibility as $Q$ tends to zero as given by

$$
I(Q \longrightarrow 0)=\rho k_{B} T \chi_{T} Z,
$$

where $Z$ is the total number of electrons in a single molecule, $k_{B}$ is the Boltzmann constant, $T$ is the absolute temperature, and $\chi_{T}$ is the isothermal compressibility.

There are many different formalisms for the total structure factor $S_{X}(Q)$. Experimentally, they all derive from the measured elastically scattered intensity $I_{X}(Q)$ by subtracting a form factor $f^{2}(Q)$ approximating the electron density (self scattering of the atoms or molecules) and the Compton scattering contribution, $C(Q)$. The most common is to divide by the average scattering $\left\langle f^{2}(Q)\right\rangle$,

$$
S_{X}(Q)-1=\frac{I_{X}(Q)-\left(\sum_{i=1}^{n} f_{i}^{2} Q\right)-C(Q)}{\left\langle f^{2}(Q)\right\rangle},
$$

where $i$ and $j$ represent the different atomic species in the molecule [31-33]. For molecules or well defined "molecular units" we can define a function,

$$
\begin{aligned}
& S_{\text {molecule }}(Q) \\
& \quad=\sum_{i, j=1}^{m} \frac{N c_{i} c_{j} f_{i}(Q) f_{j}(Q)}{2} \operatorname{sinc}\left(Q r_{i j}\right) \exp \left(-Q^{2} \sigma_{i j}\right),
\end{aligned}
$$

where

$$
S_{X}(Q)=S_{\text {molecule }}(Q)+S_{\text {inter-molecule }}(Q) .
$$

$N$ denotes the coordination number, $r_{i j}$ are the intramolecular atomic separations, and $\sigma_{i j}$ are the associated mean squared displacements. The nonspherical shape of the electron cloud in liquids or glasses with few electrons, such as hydrogenous materials, requires a redistribution of charge to be taken into account. This affects the shape of the $S(Q)$ at low $Q$-values that is, $Q \leq 2 \AA^{-1}$. In the case of water the spherical independent atom approximation form factors have been successfully modified to give the Modified Atomic Form Factor (MAFF) through [34],

$$
f_{\alpha}^{\mathrm{MAFF}}(Q)=\left[1-\frac{Z_{\alpha}}{f_{\alpha}(0)} \exp \left(-\frac{Q^{2}}{2 \delta_{\alpha}^{2}}\right)\right] f_{\alpha}(Q),
$$

where $Z$ is the fractional electron charge on the $\alpha$ atoms and it is required that $\sum_{\alpha} Z_{\alpha}=0$ to conserve charge.

Given the electron density approximation, a (pseudonuclear) pair distribution function $G_{X}(r)$ can be defined via a Sine Fourier transformation,

$$
G_{X}(r)-1=\frac{1}{2 \pi^{2} r \rho} \int_{Q_{\min }}^{Q_{\max }} Q\left[S_{X}(Q)-1\right] \sin (Q r) d Q,
$$

where $Q_{\min }$ and $Q_{\max }$ represent the finite range in reciprocal space over which the X-ray data are measured and $\rho$ is the atomic (or molecular) number density in $\AA^{3}$. Of these two limits the $Q_{\max }$ often has the most noticeable effect on the Fourier transform, especially at low-r, as the $S_{X}(Q)$ curve should be truncated at precisely 1.0 at a node, to avoid transforming a step function. A Lorch [35] or other modification function is often used to minimize the oscillations generated during the Fourier transform over a finite $Q$-range. Some useful software packages used to reduce the measured X-ray diffraction pattern to the structure 
factor and pair distribution function include ISOMERX [36], FIT2D [37], PDFGETX2 [25], and GSAS-II [38].

\section{Advantages}

High energy X-rays or "hard" rays typically have energies of $60 \mathrm{keV}-150 \mathrm{keV}$, about one order of magnitude higher than conventional X-rays [39]. The main advantages of conducting these experiments on liquids and glasses using high energy photons include the following.

(i) High-momentum transfers can be accessed, leading to high-real space resolution at short distances in the pair distribution function. This can aid in accurately distinguishing between two average bond distances which are very close together, for example.

(ii) The high penetration allows experiments to be conducted in air and in transmission geometry, in which the scattering is concentrated in the forward direction with minimal polarization effects. This allows the use of a variety of sophisticated sample environments and a straightforward detector arrangement.

(iii) Photo-absorption strongly depends on the atomic number of the material and is greatly reduced at higher energies, so heavy element containing samples can be studied.

(iv) Radiation damage, particularly from biological samples, is greatly reduced.

(v) The measured X-ray structure factors and corresponding pair distribution functions are directly comparable to neutron diffraction studies measured over similarly wide $Q$-ranges.

Of all these, the two most exploited advantages at the APS have been (ii) on liquids at extreme conditions and (v) on glasses where a section of the same sample can be used in both experiments.

\section{Experiments on Glasses and Liquids}

Early papers in the field of glasses using high energy X-ray diffraction focused on classic network glass formers such as $\mathrm{SiO}_{2}$ [13], $\mathrm{GeO}_{2}$ [14], $\mathrm{P}_{2} \mathrm{O}_{5}$ [40], and $\mathrm{B}_{2} \mathrm{O}_{3}$ [41], as well as tellurite [42], iron phosphate [43], and calcium aluminate glasses [44]. The structure of liquid $\mathrm{ZnCl}_{2}$ [45], iron trichloride [46], and methanol [47] were also studied. The field of isotopic quantum effects in hydrogen bonded molecular liquids originally studied using gamma-ray diffraction was revitalized, focussing on the deuterium effect in water [48] and methanol [49-51]. The high energy X-ray diffraction studies of glasses [52-55] can be broadly split into three main areas, oxides (e.g., silicates, germinates, borates and aluminates, etc.), chalcogenides and chalcohalides, and Bulk Metallic Glasses (BMG's).

Oxide glasses have particular relevance in geoscience and technology and include soda-lime window glass, borosilicate pyrex glass, lead oxide glassware, aluminosilicate fiberglass, and aluminate glass fiber optics. Much of the research has focused on the short and intermediate range order in silicates [57-65], Na-silicates [66, 67], germanates [68], borates [6971] aluminates [72-74], and aluminosilicates [44, 75, 76]. XRD PDF data on oxide glasses is highly complimentary to neutron diffraction PDF data since neutrons are more sensitive to the oxygen atoms, often providing a stark contrast in the partial structure factor weighting factors. Phosphate glasses [77-84] represent an important class of polymeric and molecular oxide glasses with similar applications to silicates, such as radioactive waste containment and optical fibers as well as biochemistry. Extensive studies have been carried out by Hoppe and coworkers on phosphates doped with rare-earth ions including; La [77], $\mathrm{Ga}[78], \mathrm{Fe}$ [79], $\mathrm{Pb}$ [80], $\mathrm{Zn} \mathrm{[81],} \mathrm{and} \mathrm{Ti} \mathrm{[82].} \mathrm{Hoppe}$ et al. [77-82] developed a set of rules for network changes upon the addition of modifying atoms to describe the disruption of P-O-P bonding units as a function of $\mathrm{P}_{2} \mathrm{O}_{3}$ content.

Chalcogenide glasses contain a major constituent from a group 16 element of the periodic table. These network glasses are covalently bonded like oxides but can also form homopolar bonds making a richer combination of structural motifs. Modern technological applications include mouldable intra-red optics and fibers, lenses, memory devices, and phase change materials. High energy X-ray diffraction studies have been carried out on selenides [8591], for example, see Figure 4, sulfides [92-98], arsenides [96-98], tellurites [99-104], and chalcohalides [105-107]. Bychkov et al. found a complex variation in network formation and destruction versus composition in binary chalcogenides [85]. Chemical ordering effects [98] and conduction pathways in fast-ion conducting chalcogenide glasses have also been an area of significant interest relating structure to changes in ion transport $[87,88,94,95,105-$ 107].

Bulk metallic glasses are generally made in small batches by rapid cooling methods to produce strong materials with good electrical conductivity. High energy X-ray diffraction is well suited to the study of BMG's [108-130] because of the high signal/background signal and both binary [113-117] and multicomponent $[118,121]$ systems have been studied extensively using the HEXRD technique. Of particular interest has been structural ordering upon supercooling $[119,120]$, thermal behavior $[121,122]$, and correlating the mechanical or tensile behavior with local distortions in the local structure [123-126]. Attention has also been paid to their glass forming ability $[127,128]$ and an important theme has been identifying structural heterogeneities in the deeply supercooled melt $[129,130]$.

In the case of liquids, several metals and alloys [131134] have been studied in the molten state, along with $\mathrm{Ge}$ [135], tellurites [136, 137], aluminates [138, 139], silicates [140], and aluminosilicates [141]. Molecular liquids have also been investigated extensively with high energy X-ray diffraction, including the electron density in water [142], the effect of strong hydrogen bonding in deeply supercooled water [143], flourides [144-150], the structure of molten 


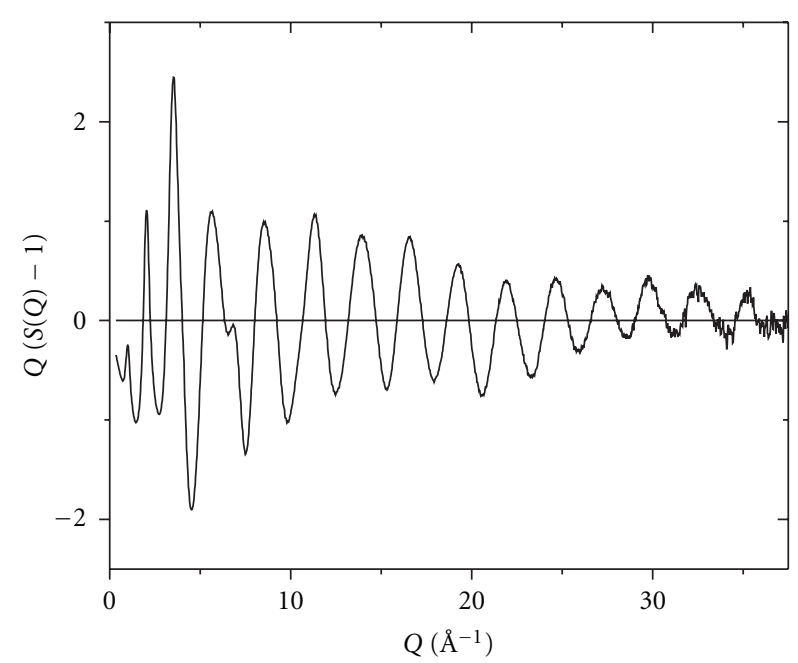

(a)

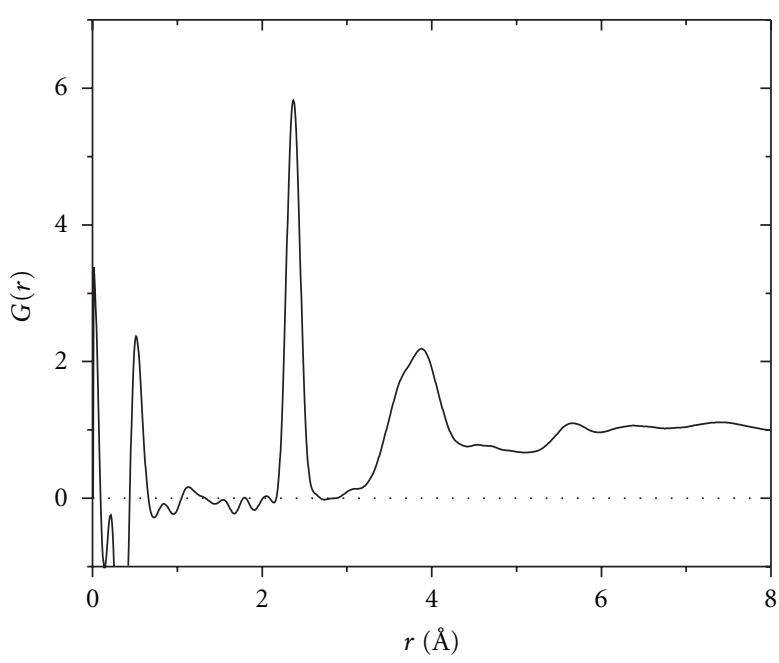

(b)

FIgURE 4: High energy X-ray diffraction data on $\mathrm{GeSe}_{2}$ glass measured on beamline 11-ID-C at the Advanced Photon Source. (a). The X-ray structure factor. (b). The corresponding pair distribution function. Courtesy of L. Skinner.

salts [151, 152], as well as temperature and compositiondependent intermediate range order in ionic liquids [153-163]. The structural chemistry of actinide solutions has also been explored [164-168]. Experiments on these radioactive liquids and highly corrosive acids $[146,147,150]$ have led to the design of specialized containers [169] which the high energy X-rays are able to penetrate.

High energy X-ray scattering techniques have been effectively used to measure the electron density distribution differences between light and heavy water [48, 142, 170-172], benzene [173], methanol [49-51, 174], ethanol [175], as well as amorphous hydrides $[176,177]$. Since the electronic scattering is essentially the same for both $\mathrm{H}$ and $\mathrm{D}$, changes in the zero point energies lead to subtle changes in both the intra- and intermolecular structures. These isotope quantum effects obtained by comparing X-ray diffraction from the hydrogenous and selectively deuterated forms of molecular liquids have important implications for the accuracy of the H/D substitution technique in neutron diffraction. The deuterated liquids have a more rigid (ordered structure), and the hydrogenous liquids more quantum mechanical. Computer simulations suggest that the substitution is essentially equivalent to reducing the quantum mechanical effects by half in liquid water upon deuteration [48]. This has led to comprehensive studies of temperature $[170,171]$ and density [178] dependent deuteration effects (see Figure 5) which will hopefully lead to the development of better intermolecular potentials.

Amorphous solids usually refer to disordered materials which are produced by means other than quenching the liquid (chemical reactions, vapour deposition, etc.) and do not exhibit a glass transition temperature. High energy Xray diffraction studies of technological importance on amorphous materials include calcium-silicate hydrate cements [179-182], bioactive foams [183], amorphous zeolites [184, 185], spider silk fibers [186], and electronic materials [187, $188]$.

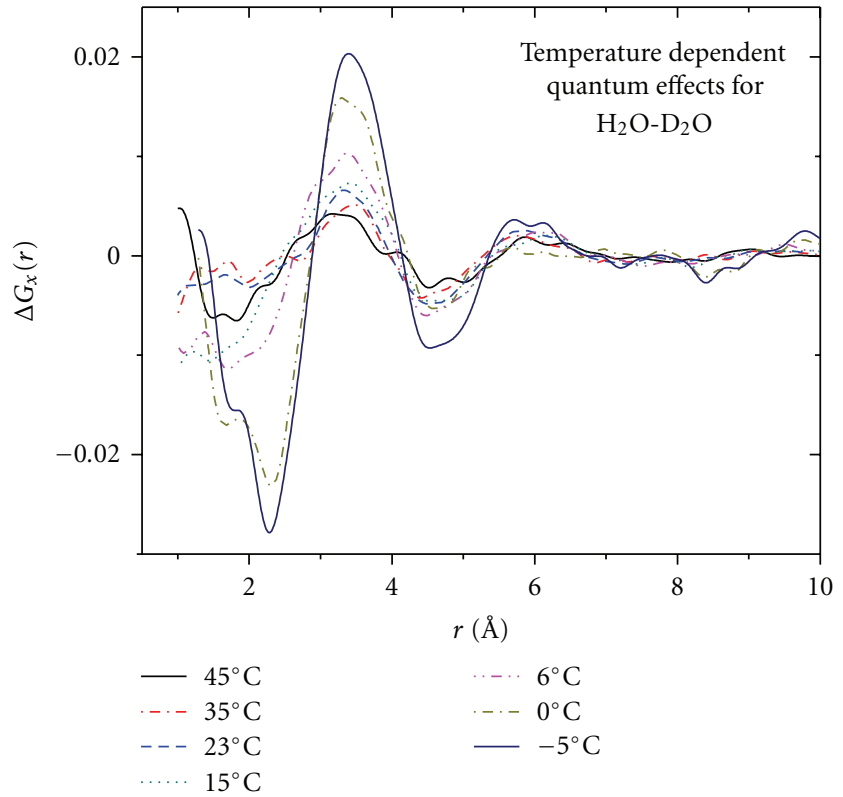

FIGURE 5: The difference between the electronic distribution functions of light and heavy water as a function of temperature.

\section{Extreme Environments}

Increasingly, materials need to be measured under realistic, sometimes extreme, conditions and over a range of timescales.

The effect of high pressure on the structure of glass have been of interest since the pioneering work of Bridgman in the 1950's [189]. Densified glasses subjected to high pressures and recovered to ambient pressures generally show a significant loss of intermediate range order but very little change in short range ordering [190-193]. Moissanite [194] and Diamond Anvil Cell measurements [195-208] on glasses 


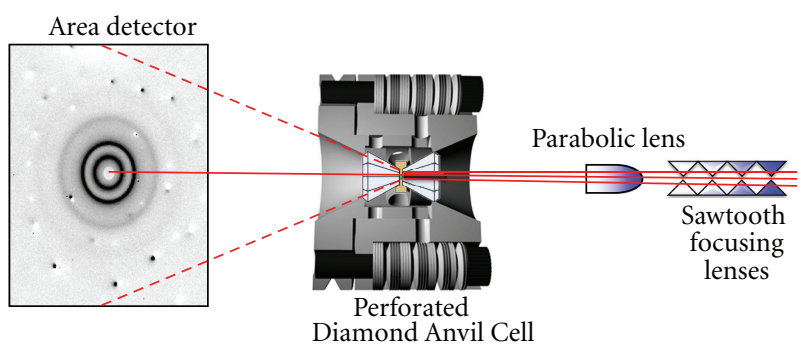

Figure 6: A schematic of the high pressure Perforated Diamond Cell set up on 1-ID. Adapted from a talk by E. Soignard.

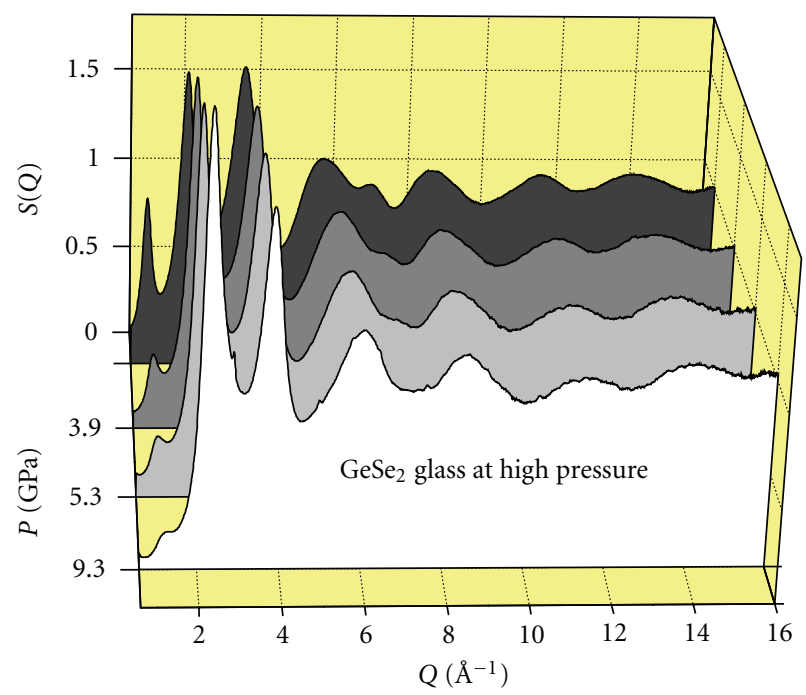

FIGURE 7: X-ray structure factors for $\mathrm{GeSe}_{2}$ glass at high pressure measured in a Diamond Anvil Cell at beamline 1-ID at the APS.

have been able to achieve several tens of GPa's leading to much larger changes in structural packing as well as local coordination number changes, for example, see Figure 6. In addition to the single crystal Bragg scattering which has to be removed during the data analysis procedure, the large Compton scattering contribution from the diamond has been greatly reduced by perforating one of the diamonds [209]. The study of silicate glasses at high pressure has attracted interest from the geological community from the point of view of understanding the atomic structure and transitions that occur in magmas within the Earths mantle $[202,206]$. The densification of chalcogenide glasses [194, 195, 198, $200,206]$ with pressure are more complex due to the propensity of homopolar bonding (see Figure 7) and offer the possibility of forming high-density glasses which may be retained at ambient pressure [194]. Some current trends include measurements under hydrostatic conditions [203] and the development of new pressure cells to explore new regions of the liquid phase diagram not previously accessed by high energy X-ray diffraction [209]. These include the a hydrothermal (HDAC) cell design aimed at accessing low pressures and high temperatures [209], and gas pressure cells with low-background amorphous carbon windows ideal for studying poorly scattering aqueous solutions. Measuring strain distributions in amorphous materials also continues to be a topic of significant interest [210-212].

For glasses, the study of (usually) small structural changes around the glass transition temperature which may be associated with large changes in the dynamical behavior occuring has been of particular interest [56, 213-229]. This has led to the development of rapid data acquisition methods (up to $\sim 100 \mathrm{~ms}$ ) applied to glass forming liquids upon cooling from very high temperatures [215-219] as well as studies of the stable melts [220-224]. Time-resolved measurements have been made on supercooled oxide liquids held in aerodynamic levitators from temperatures up to $2500^{\circ} \mathrm{C}$ [225-227] (see left hand side of Figure 8) and liquid metals suspended in electrostatic levitators [228, 229]. Recently acoustic levitation combined with high energy Xray diffraction (see right hand side of Figure 8) has been used to study the structure of supercooled, glassy, and amorphous organic liquids and solutions at temperatures down to $-20^{\circ} \mathrm{C}$ [230]. An interesting new application using this technique is the application for making and characterizing fast acting amorphous drugs [231, 232]. The ability to model different molecular conformations of amorphous drugs made using different methods and compare the results directly to the pair distribution function could provide useful information to the pharmaceutical industry.

It has long been known that glasses and amorphous solids are by definition inherently polyamorphic, since their exact structure depends on the route by which they were produced. However in recent years the term "polyamorphism" in liquids has come to be associated with a first order phase transition between two distinct structural forms of the same material [233-235]. Since many of the proposed transitions occur at extreme conditions, high energy X-ray diffraction has been used extensively in this area to identify different structures of potential polyamorphic materials. The abrupt transition(s) observed between different density forms of amorphous ice has often been used as an analogy with what could occur in the liquid state, and the X-ray diffraction patterns at different densities are strikingly different [236241]. High temperature aerodynamic levitation has also been used to investigate the two phase structure of liquid and glassy yttria aluminates [242-247], for example, see Figure 9, and low temperature measurements have been carried out to characterize the so-called glacial state of the molecular liquid triphenyl phosphite [248-250].

\section{Data Interpretation}

The most common way of interpreting total scattering data is to use the Faber-Ziman formalism [251] which defines element specific partial structure factors. Other formalisms are occasionally used in the literature by various groups and have been summarized by Keen [252]. There are also several different variations for representing the Faber-Ziman partial structure factors and partial pair distribution functions, used by different communities to highlight different aspects of the patterns. Here we describe the Hannon-Howells-Soper 


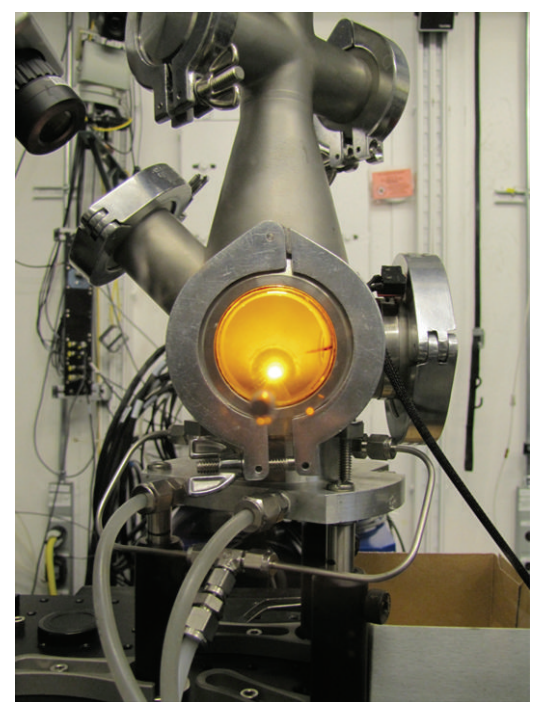

(a)

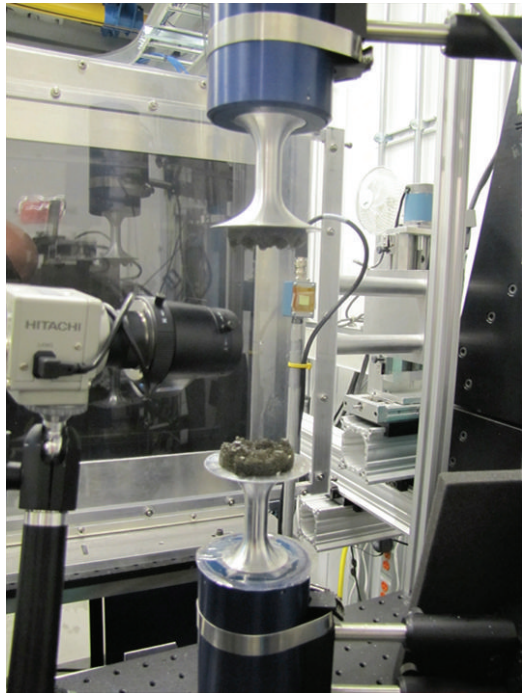

(b)

Figure 8: (a) A laser-heated sample in the aerodynamic levitator chamber. The chamber totally encloses the X-ray beam to enable a class I system operation despite containing an embedded class IV laser. (b) An acoustic levitator, comprising of two transducers (blue) with a camera focused on the levitated droplet and an area detector in the background.

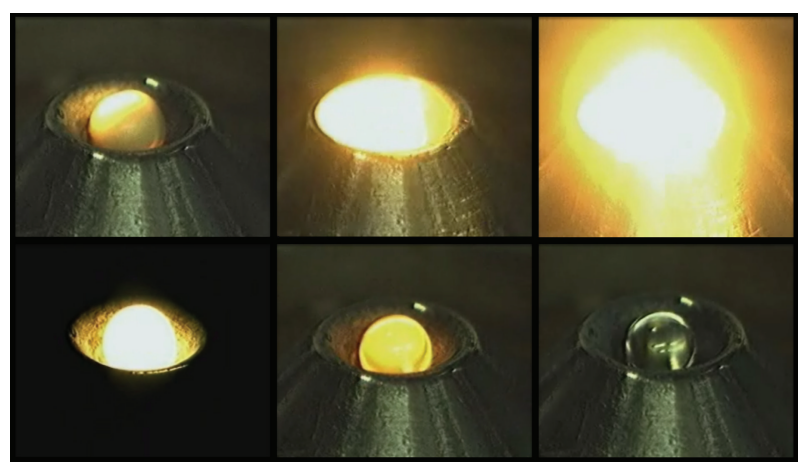

Figure 9: A time dependent sequence showing the melting and subsequent vitrification of an oxide melt in the aerodynamic levtator.

formalism [252] commonly used for liquids and glasses where for X-rays,

$$
S_{X}(Q)=\sum_{\alpha, \beta} \frac{c_{\alpha} f_{\alpha}(Q) c_{\beta} f_{\beta}(Q)}{\left\langle f^{2}(Q)\right\rangle}\left[S_{\alpha \beta}(Q)-1\right]
$$

where $\alpha$ and $\beta$ represent different atom types. A discussion of the density related behavior of the intensity of the so-called "first sharp diffraction peak" related to intermediate range ordering compared to that of the second diffraction peak (related to chemical or extended range ordering) in several binary liquids and amorphous materials has been given by Benmore et al. [253]. The Sine Fourier transform given in (8) yields the pair distribution function $G_{X}(r)$ which is commonly used by the liquids community to emphasize local structure. The neutron glass community on the other hand tends to use the distribution function $T_{X}(r)=4 \pi \rho r G_{X}(r)$ since the resolution function is symmetric leading to more accurate fitting for extracting coordination numbers [23]. However, for X-rays peak and coordination number fitting is often done in $Q$-space using equation (6) due to the need to include $Q$-dependent form factors [33]. The differential distribution function $D_{X}(r)=4 \pi \rho r\left[G_{X}(r)-1\right]$ with the bulk density removed is used for glasses and molecular liquids to highlight ordering at longer distances or for systems where the density is not known [23]. Expressing the $G_{X}(r)$ representation in terms of partial distribution functions is not so straight forward as for neutron diffraction because the element specific partial weighting factors in reciprocal space are $Q$-dependent. The expression can be simplified by using the approximation $f_{\alpha}(Q) /\left\langle f^{2}(Q)\right\rangle \simeq$ $f_{\alpha}(0) /\left\langle f^{2}(0)\right\rangle$, where $f_{\alpha}(0)=Z_{\alpha}$ as has been described by Neuefeind and Poulsen [13] and Keen [252].

The Bhatia-Thornton formalism [254] is also sometimes used to provide information on the topology and chemical ordering in a liquid or a glass. For a binary system the Bhatia-Thornton representation is straight-forwardly linked to the Faber-Ziman formulation using linear equations which convert the element specific partials to the numbernumber, concentration-concentration, and the cross term number-concentration partial structure factors. The BhatiaThornton formalism has been successfully used to explore the extent of longer range correlations in real space known as "extended range ordering" [255]. However the magnitude of these oscillations show that the degree ordering only represents a very small fraction of the bulk material [256].

Partial extraction or elimination of one or a group of partial structure factors from the measured total is most commonly achieved experimentally by combining high energy X-ray diffraction data with other techniques, such as neutron diffraction or anomalous X-ray diffraction. 
Various first or even second order difference functions may be extracted if there is sufficient contrast, to extract information on a particular feature of interest. EXAFS is also commonly used to help remove element specific peaks of a known coordination number from the total pair distribution function. Nuclear Magnetic Resonance and to some extent Raman scattering provides complementary information on the speciation of certain elements which cannot be directly accessed using diffraction data alone, but may be used a strong constraints on the interpretation of X-ray PDF data.

\section{Main Limitations of the Technique}

By far the largest limitation of high energy X-ray scattering is the rapidly decaying $\mathrm{X}$-ray form factor signal compared to the growing Compton scattering (background) contribution at high- $Q$ values, making the accurate extraction of $S_{X}(Q)$ over the widest accessible $Q$-range problematic. At the highest $Q$-values, for example, $>30 \AA^{-1}$, small corrections of less than a percent from the source, sample, and detector become magnified, leading to greater statistical and systematic errors, such that accurate normalization in absolute units becomes increasingly difficult. The situation is worst for low$Z$ materials. In addition, currently the most information that can be reliably extracted from an X-ray experiment from an isotropic glass or liquid is a one-dimensional distribution function from which the three-dimensional structure cannot be directly generated. The X-ray data therefore represent an average overview of the structure from which only the first few peaks in the pair distribution function can typically be used to extract accurate atom-atom distances and coordination numbers.

\section{Simulation and Modeling}

In practically all cases a complete structural picture of the liquid or glass can only be achieved with the help of some sort of computer modeling or simulation. Inverse methods such as Reverse Monte Carlo (RMC) [257, 258], Emprical Potential Structure Refinement (EPSR) [34, 172, 259] are now widely used to interpret high energy $\mathrm{X}$-ray and neutron diffraction data since they provide a 3-dimensional atomic (or molecular model) which exactly fits the measured data within the errorbars. To a lesser extent, disordered crystal models for fitting pressure induced amorphization diffraction patterns have also been successfully employed [260]. RMC works when the interactions in the system are pairwise additive and has been mainly used for studying glasses, amorphous materials, and melts, for example, [66, 70, 261]. The process tends to produce the most disordered structure associated with the measured data and the more constraints that are used the more realistic the model becomes. EPSR was designed primarily for interpreting diffraction data from molecular liquids but uses an empirical potential to drive the fitting process. Both methods can be considered as analogues of the Reitveld fitting process in crystallography and will provide partial structure factors, bond angle distributions, and ring statistics information.

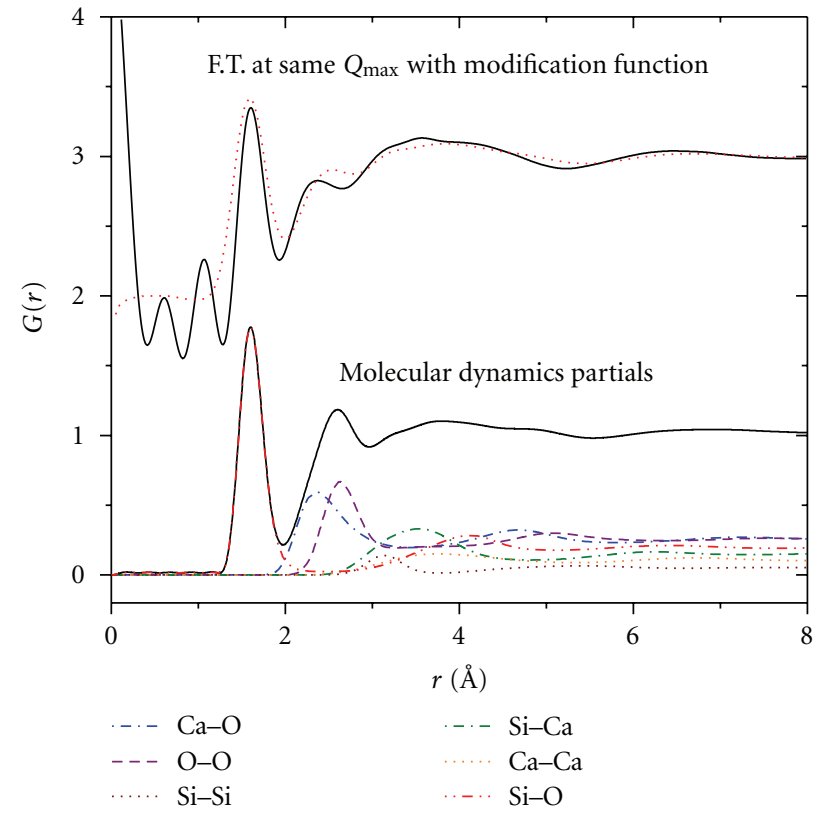

Figure 10: The measured X-ray pair distribution function for liquid $\mathrm{CaSiO}_{3}$ (black solid line, top) compared to that calculated from a molecular dynamics simulation (red dotted line, top) both truncated at a $Q_{\max }=19 \AA^{-1}$ and Fourier transformed (F.T.) with the same Lorch modification function applied. The bottom set of curves shows the individual X-ray weighted partial pair distribution functions calculated directly from the MD simulation box [56].

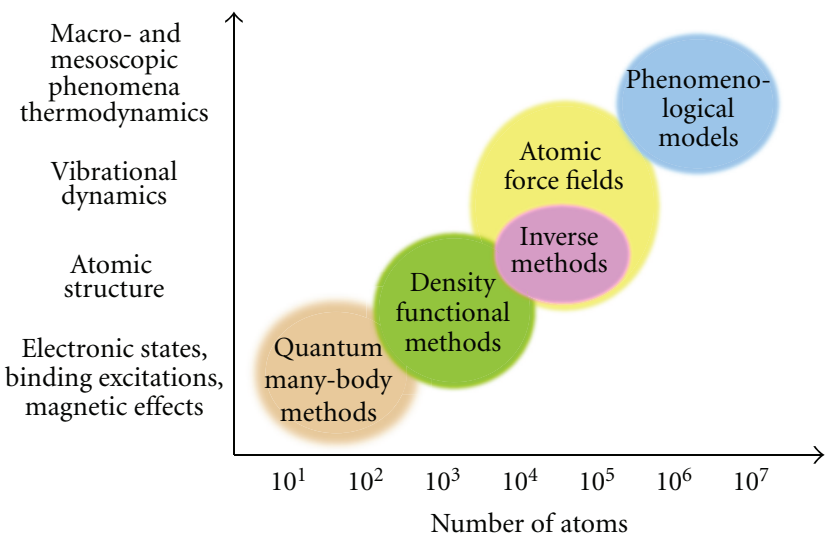

Figure 11: A schematic of the nature of different simulation techniques versus the number of atoms in the model box.

To model the underlying physics of the inter-atomic or intermolecular interactions Molecular Dynamics (MD) $[262,263]$ or Density Functional Theory (DFT) [264] have commonly been used. Accurate inter-atomic potentials for both oxide and nonoxide glasses have been developed that closely resemble the measured X-ray and neutron structure factors and pair distribution functions (see Figure 10). Hopefully these potentials, which are based on a realistic structural model, may be relied upon to predict reasonable dynamical behavior. Both MD and DFT have been combined with an atomic starting configuration based on RMC models 


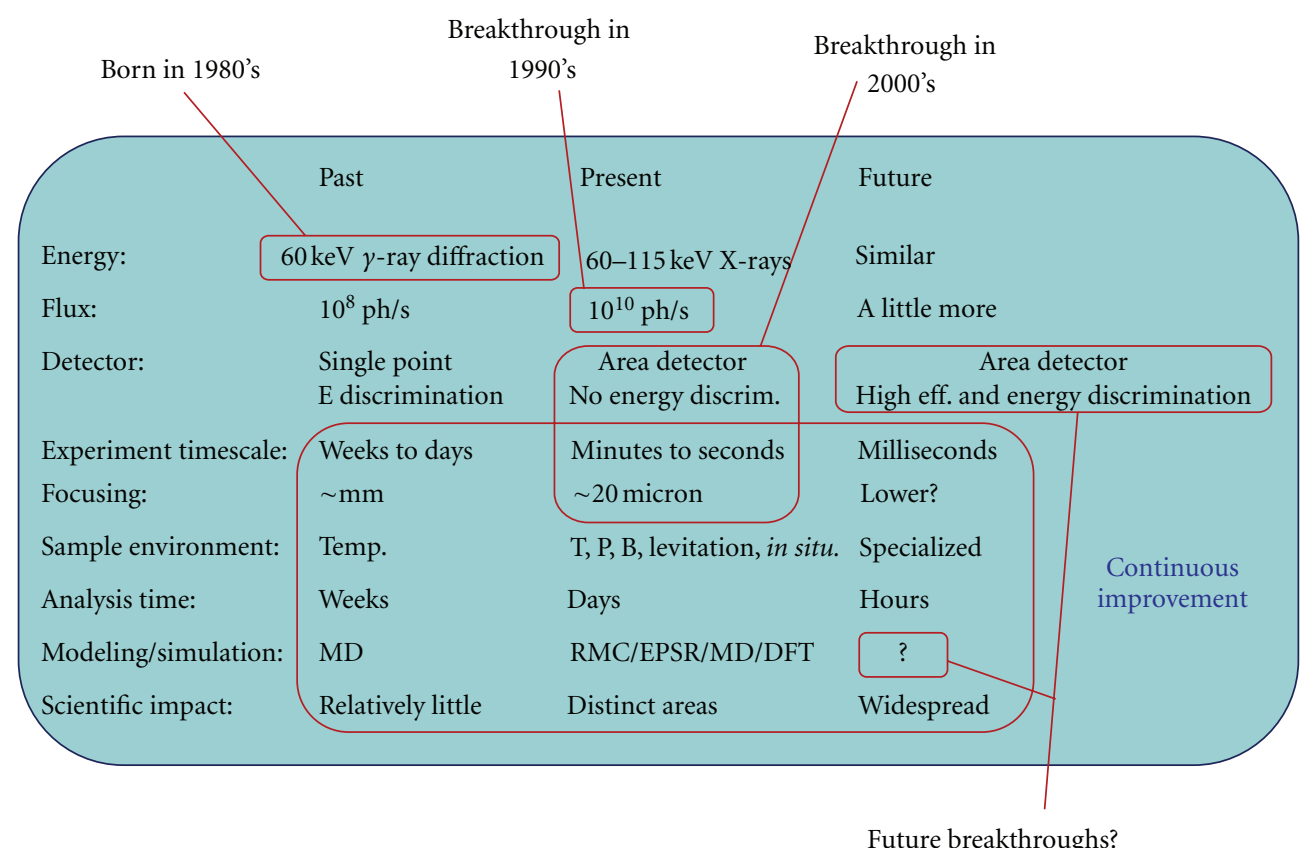

Figure 12: A schematic of my personal view of the birth and development of high energy X-ray diffraction over the past few decades and future opportunities.

$[74,239,265]$. These combined theoretical and experimental approaches represent a major step forward as the electronic structure and bond ordering information can be obtained from the DFT calculation as well as a prediction of the NMR spectrum.

A schematic of the different simulation methods as a function of the number of atoms is shown in Figure 11. These range from detailed quantum many-body method calculations to large scale mesoscopic and macroscopic phenomenological models.

\section{Future}

A schematic of the past, present, and future developments of high-energy X-ray diffraction from liquids and glasses is shown in Figure 12. The figure identifies some major breakthroughs in the field and predicts opportunities for further growth such as detector and software development.

The future of high energy X-ray diffraction science at 11-ID-C at the Advanced Photon Source lies in the design of complex sample environments for the study of energyrelated materials under realistic conditions. The combination of magnetic and/or electric fields, pressure, and low/high temperature as well as time resolved studies is already in progress. The advances in time-resolved measurements will allow chemical reactions in liquids to be followed in situ on the beamline. Also, the question of structural heterogenity between the ergodic and nonergodic regimes during glass formation may now be accessed for a wider range of glassforming liquids. To achieve this smaller, more intense photon beams are required with energy discriminating large area detectors, which are not currently available. Nanoparticles have not been mentioned in this paper but as the interface between lengthscales blends together the study of bulk versus surface effects represents another area of research which maybe extended to glasses and amorphous materials at interfaces. Lastly, more sophisticated software is needed to process the huge amount of data generated. Advances in computational scattering science are necessary to make full use of the data we already measure and interpret the ever increasing complexity of our experiments [266].

\section{Acknowledgments}

Many people have contributed greatly to this work. In particular the author wishes to thank Dr. J. K. R. Weber, Professor J. L. Yarger, Professor J. B. Parise, Dr. L. B. Skinner, Dr. J. Neuefeind, Dr. Y. Ren, Dr. J. Du, Dr. S. Kohara, and Professor P. A. Egelstaff.

\section{References}

[1] B. E. Warren, "The diffraction of X-rays in glass," Physical Review, vol. 45, no. 10, pp. 657-661, 1934.

[2] B. E. Warren, "X-ray determination of the structure of liquids and glass," Journal of Applied Physics, vol. 8, no. 10, pp. 645654, 1937.

[3] J. Morgan and B. E. Warren, "X-ray analysis of the structure of water," The Journal of Chemical Physics, vol. 6, no. 11, pp. 666-673, 1938.

[4] A. H. Narten, "X-ray diffraction pattern and models of liquid benzene," The Journal of Chemical Physics, vol. 67, no. 5, pp. 2102-2108, 1977.

[5] A. H. Narten and A. Habenschuss, "Hydrogen bonding in liquid methanol and ethanol determined by X-ray diffraction," 
The Journal of Chemical Physics, vol. 80, no. 7, pp. 3387-3391, 1984.

[6] A. J. Leadbetter and A. C. Wright, "Diffraction studies of glass structure III. Limitations of the fourier method for polyatomic glasses," Journal of Non-Crystalline Solids, vol. 7, no. 2, pp. 141-155, 1972.

[7] A. J. Leadbetter and A. C. Wright, "Diffraction studies of glass structure IV. The structure of vitreous BeF2by X-ray and neutron diffraction," Journal of Non-Crystalline Solids, vol. 7, no. 2, pp. 156-167, 1972.

[8] A. C. Wright, A. G. Clare, D. I. Grimley, and R. N. Sinclair, "Neutron scattering studies of network glasses," Journal of Non-Crystalline Solids, vol. 112, no. 1-3, pp. 33-47, 1989.

[9] A. C. Wright, "Diffraction studies of glass structure," Journal of Non-Crystalline Solids, vol. 123, no. 1-3, pp. 129-148, 1990.

[10] A. C. Wright, "Neutron scattering from vitreous silica. V. The structure of vitreous silica: what have we learned from 60 years of diffraction studies?" Journal of Non-Crystalline Solids C, vol. 179, pp. 84-115, 1994.

[11] P. A. Egelstaff, "Radiation scattering data on liquid metals," Advances in Physics, vol. 16, no. 62, pp. 147-169, 1967.

[12] J. H. Root, P. A. Egelstaff, and A. Hime, "Quantum effects in the structure of water measured by gamma ray diffraction," Chemical Physics, vol. 109, no. 2-3, pp. 437-453, 1986.

[13] J. Neuefeind and H. F. Poulsen, "Diffraction on disordered materials using 'neutron-like' photons," in Proceedings of the Euroconference' 94 on Neutrons in Disordered Matter, pp. 112116, June 1994.

[14] J. Neuefeind and K. D. Liss, "Bond angle distribution in amorphous germania and silica," Berichte der Bunsengesellschaft, vol. 100, no. 8, pp. 1341-1349, 1996.

[15] J. Neuefeind, M. D. Zeidler, and H. F. Poulsen, "The atomic and electronic structure of liquid N-methylformamide as determined from diffraction experiments," Molecular Physics, vol. 87, no. 1, pp. 189-201, 1996.

[16] S. Kohara, K. Suzuya, Y. Kashihara, N. Matsumoto, N. Umesaki, and I. Sakai, "A horizontal two-axis diffractometer for high-energy X-ray diffraction using synchrotron radiation on bending magnet beamline BL04B2 at SPring-8," Nuclear Instruments and Methods in Physics Research A, vol. 467-468, no. II, pp. 1030-1033, 2001.

[17] S. Kohara and K. Suzuya, "High-energy X-ray diffraction studies of disordered materials," Nuclear Instruments and Methods in Physics Research B, vol. 199, pp. 23-28, 2003.

[18] R. Bouchard, D. Hupfeld, T. Lippmann et al., "A triplecrystal diffractometer for high-energy synchrotron radiation at the HASYLAB high-field wiggler beamline BW5," Journal of Synchrotron Radiation, vol. 5, no. 2, pp. 90-101, 1998.

[19] U. Rütt, M. A. Beno, J. Strempfer, G. Jennings, C. Kurtz, and P. A. Montano, "Diffractometer for high energy X-rays at the APS," Nuclear Instruments and Methods in Physics Research A, vol. 467-468, no. II, pp. 1026-1029, 2001.

[20] J. Neuefeind, "High energy XRD investigations of liquids," Journal of Molecular Liquids, vol. 98-99, pp. 87-95, 2002.

[21] P. A. Egelstaff, "Structural quantum effects in hydrogeneous liquids and glasses Part II experiments using synchrotron radiation," Physics and Chemistry of Liquids, vol. 41, no. 2, pp. 109-121, 2003.

[22] S. Kohara, M. Itou, K. Suzuya et al., "Structural studies of disordered materials using high-energy X-ray diffraction from ambient to extreme conditions," Journal of Physics Condensed Matter, vol. 19, no. 50, Article ID 506101, 2007.
[23] A. J. G. Ellison, R. K. Crawford, D. G. Montague, K. J. Volin, and D. L. Price, "The new glass liquid and amorphous materials diffractometer (GLAD) at IPNS," Journal of Neutron Research, vol. 1, no. 4, pp. 61-40, 1993.

[24] L. B. Skinner, C. J. Benmore, and J. B. Parise, "Area detector corrections for high quality synchrotron X-ray structure factor measurements," Nuclear Instruments \& Methods in Physics Research Section, vol. A662, no. 1, p. 61, 2012.

[25] X. Qiu, E. S. Božin, P. Juhas, T. Proffen, and S. J. L. Billinge, "Reciprocal-space instrumental effects on the realspace neutron atomic pair distribution function," Journal of Applied Crystallography, vol. 37, no. 1, pp. 110-116, 2004.

[26] J. Zaleski, G. Wu, and P. Coppens, "On the correction of reflection intensities recorded on imaging plates for incomplete absorption in the phosphor layer," Journal of Applied Crystallography, vol. 31, no. 2, pp. 302-304, 1998.

[27] H. H. Paalman and C. J. Pings, "Numerical evaluation of Xray absorption factors for cylindrical samples and annular sample cells," Journal of Applied Physics, vol. 33, no. 8, pp. 2635-2639, 1962.

[28] A. K. Soper, "Multiple scattering from an infinite plane slab," Nuclear Instruments and Methods In Physics Research, vol. 212, no. 1-3, pp. 337-347, 1983.

[29] A. K. Soper and P. A. Egelstaff, "Multiple scattering and attenuation of neutrons in concentric cylinders: I. Isotropic first scattering," Nuclear Instruments and Methods, vol. 178, no. 2-3, pp. 415-425, 1980.

[30] M. Ali, K. Marasinghe, R. Hart, C. Benmore, N. Wyckoff, and R. Brow, "Normalisation and sample composition analysis of binary rare earth phosphate glasses by high energy X-ray scattering," Physics and Chemistry of Glasses B, vol. 47, no. 2, pp. 146-149, 2006.

[31] A. H. Narten and H. A. Levy, "Liquid water: molecular correlation functions from X-ray diffraction," The Journal of Chemical Physics, vol. 55, no. 4, pp. 2263-2269, 1971.

[32] A. H. Narten and H. A. Levy, "Observed diffraction pattern and proposed models of liquid water," Science, vol. 165, no. 3892, pp. 447-454, 1969.

[33] A. H. Narten, "Diffraction pattern and structure of noncrystalline bef 2 and $\mathrm{SiO}_{2}$ at $25^{\circ} \mathrm{C}$," The Journal of Chemical Physics, vol. 56, no. 5, pp. 1905-1909, 1972.

[34] A. K. Soper, "Joint structure refinement of X-ray and neutron diffraction data on disordered materials: application to liquid water," Journal of Physics Condensed Matter, vol. 19, no. 33, Article ID 335206, 2007.

[35] E. Lorch, "Neutron diffraction by germania, silica and radiation-damaged silica glasses," Journal of Physics C, vol. 2, no. 2, pp. 229-237, 1969.

[36] J. Urquidi, C. J. Benmore, J. Neuefeind, Tomberli, and B. Isomer-X, "A program for the analysis of high-energy X-ray diffraction experiments," Journal of Applied Crystallography, vol. 36, p. 368, 2003.

[37] A. P. Hammersley, S. O. Svensson, M. Hanfland, A. N. Fitch, and D. Häusermann, "Two-dimensional detector software: from real detector to idealised image or two-theta scan," High Pressure Research, vol. 14, no. 4-5, pp. 235-248, 1996.

[38] GSAS-II-Crystallography Data Analysis Software, https:// subversion.xor.aps.anl.gov/trac/pyGSAS.

[39] H. E. Fischer, A. C. Barnes, and P. S. Salmon, "Neutron and X-ray diffraction studies of liquids and glasses," Reports on Progress in Physics, vol. 69, no. 1, pp. 233-299, 2006.

[40] U. Hoppe, R. Kranold, A. Barz, D. Stachel, and J. Neuefeind, "Structure of vitreous $\mathrm{P} 2 \mathrm{O} 5$ studied by high-energy X-ray 
diffraction," Solid State Communications, vol. 115, no. 10, pp. 559-562, 2000.

[41] K. Suzuya, Y. Yoneda, S. Kohara, and N. Umesaki, "High energy X-ray study of the structure of vitreous B2O3," Physics and Chemistry of Glasses, vol. 41, no. 5, pp. 282-285, 2000.

[42] J. C. McLaughlin, S. L. Tagg, J. W. Zwanziger, D. R. Haeffner, and S. D. Shastri, "Structure of tellurite glass: a combined NMR, neutron diffraction, and X-ray diffraction study," Journal of Non-Crystalline Solids, vol. 274, no. 1, pp. 1-8, 2000.

[43] Y. Badyal, M. Karabulut, K. Marasinghe et al., "The effects of uranium on the structure of iron phosphate glasses," in Scientific Basis For Nuclear Waste Management XXII. Materials Research Society Symposium Proceedings, D. J. Wronkiewicz and J. H. Lee, Eds., vol. 556, p. 297, 1999.

[44] V. Petkov, S. J. L. Billinge, S. D. Shastri, and B. Himmel, "Polyhedral units and network connectivity in calcium aluminosilicate glasses from high-energy X-ray diffraction," Physical Review Letters, vol. 85, no. 16, pp. 3436-3439, 2000.

[45] J. Neuefeind, K. Tödheide, A. Lemke, and H. Bertagnolli, "The structure of molten $\mathrm{ZnCl}_{2}$," Journal of Non-Crystalline Solids, vol. 224, no. 3, pp. 205-215, 1998.

[46] Y. S. Badyal, M. L. Saboungi, D. L. Price, D. R. Haeffner, and S. D. Shastri, "Atomic and electronic structure of liquid iron trichloride," Europhysics Letters, vol. 39, no. 1, pp. 19-24, 1997.

[47] T. Weitkamp, J. Neuefeind, H. E. Fischer, and M. D. Zeidler, "Hydrogen bonding in liquid methanol at ambient conditions and at high pressure," Molecular Physics, vol. 98, no. 3, pp. 125-134, 2000.

[48] B. Tomberli, C. J. Benmore, P. A. Egelstaff, J. Neuefeind, and V. Honkimäki, "Isotopic quantum effects in water structure measured with high energy photon diffraction," Journal of Physics Condensed Matter, vol. 12, no. 12, pp. 2597-2612, 2000.

[49] B. Tomberli, C. J. Benmore, P. A. Egelstaff, J. Neuefeind, and V. Honkimäki, "Temperature dependence of structural quantum effects in liquid methanol," Europhysics Letters, vol. 55, no. 3, pp. 341-347, 2001.

[50] B. Tomberli, P. A. Egelstaff, C. J. Benmore, and J. Neuefeind, "Isotopic quantum effects in the structure of liquid methanol: I. Experiments with high-energy photon diffraction," Journal of Physics Condensed Matter, vol. 13, no. 50, pp. 11405-11420, 2001.

[51] B. Tomberli, P. A. Egelstaff, C. J. Benmore, and J. Neuefeind, "Isotopic effects in the structure of liquid methanol: II. Experimental data in Fourier space," Journal of Physics Condensed Matter, vol. 13, no. 50, pp. 11421-11434, 2001.

[52] V. Petkov, S. J. L. Billinge, S. D. Shastri, and B. Himmel, "High-resolution atomic distribution functions of disordered materials by high-energy X-ray diffraction," Journal of Non-Crystalline Solids, vol. 293-295, no. 1, pp. 726-730, 2001.

[53] H. Ohno, S. Kohara, N. Umesaki, and K. Suzuya, "Highenergy X-ray diffraction studies of non-crystalline materials," Journal of Non-Crystalline Solids, vol. 293-295, no. 1, pp. 125135, 2001.

[54] V. Petkov, "Atomic-scale structure of glasses using highenergy X-ray diffraction," Journal of the American Ceramic Society, vol. 88, no. 9, pp. 2528-2531, 2005.

[55] Y. Murakami, T. Usuki, S. Kohara, Y. Amo, and Y. Kameda, "Structure modeling for covalently bonded network glasses," Journal of Non-Crystalline Solids, vol. 353, no. 18-21, pp. 2035-2038, 2007.
[56] C. J. Benmore, J. K. R. Weber, M. C. Wilding, J. Du, and J. B. Parise, "Temperature-dependent structural heterogeneity in calcium silicate liquids," Physical Review B, vol. 82, no. 22, Article ID 224202, 2010.

[57] H. Schlenz, J. Neuefeind, and S. Rings, "High-energy X-ray diffraction study of amorphous $\left(\mathrm{Si}_{0.71} \mathrm{Ge}_{0.29}\right) \mathrm{O}_{2}$," Journal of Physics Condensed Matter, vol. 15, no. 29, pp. 4919-4926, 2003.

[58] J. A. Johnson, D. Holland, J. Urquidi, I. A. Gee, C. J. Benmore, and C. E. Johnson, "Structure of oxychloride glasses by neutron and X-ray "difference" and X-ray photoelectron spectroscopy," Journal of Physics Condensed Matter, vol. 15, no. 27, pp. 4679-4693, 2003.

[59] M. C. Wilding, C. J. Benmore, J. A. Tangeman, and S. Sampath, "Coordination changes in magnesium silicate glasses," Europhysics Letters, vol. 67, no. 2, pp. 212-218, 2004.

[60] T. Uchino, A. Aboshi, S. Kohara, Y. Ohishi, M. Sakashita, and K. Aoki, "Microscopic structure of nanometer-sized silica particles," Physical Review B, vol. 69, no. 15, Article ID 155409, pp. 1-155409, 2004.

[61] S. Kohara and K. Suzuya, "Intermediate-range order in vitreous $\mathrm{SiO}_{2}$ and $\mathrm{GeO}_{2}$," Journal of Physics Condensed Matter, vol. 17, no. 5, pp. S77-S86, 2005.

[62] T. Wakihara, T. Yamakawa, J. Tatami, K. Komeya, T. Meguro, and S. Kohara, "Nitridation of silica characterized by highenergy X-ray diffraction technique," Journal of the American Ceramic Society, vol. 90, no. 5, pp. 1562-1565, 2007.

[63] A. Mukai, S. Kohara, and T. Uchino, "Modification of medium-range order in silica glass by ball-milling: real- and reciprocal-space structural correlations for the first sharp diffraction peak," Journal of Physics Condensed Matter, vol. 19, no. 45, Article ID 455214, 2007.

[64] T. Wakihara, W. Fan, S. Kohara, M. Ogura, G. Sankar, and T. Okubo, "Intermediate-range order in mesoporous silicas investigated by a high-energy X-ray diffraction technique," Chemistry Letters, vol. 37, no. 1, pp. 30-31, 2008.

[65] Q. Mei, C. J. Benmore, S. Sen, R. Sharma, and J. L. Yarger, "Intermediate range order in vitreous silica from a partial structure factor analysis," Physical Review B, vol. 78, no. 14, Article ID 144204, 2008.

[66] M. Fábián, P. Jóvári, E. Sváb, G. Mészáros, T. Proffen, and E. Veress, "Network structure of $0.7 \mathrm{SiO}_{2}-0.3 \mathrm{Na}_{2} \mathrm{O}$ glass from neutron and X-ray diffraction and RMC modelling," Journal of Physics Condensed Matter, vol. 19, no. 33, Article ID 335209, 2007.

[67] J. A. Johnson, C. J. Benmore, D. Holland, J. Du, B. Beuneu, and A. Mekki, "Influence of rare-earth ions on $\mathrm{SiO}_{2}-\mathrm{Na}_{2} \mathrm{O}$ $\mathrm{RE} 2 \mathrm{O}_{3}$ glass structure," Journal of Physics Condensed Matter, vol. 23, no. 6, Article ID 65404, 2011.

[68] H. Schlenz, S. Rings, M. Schmücker et al., "Short-range and medium-range order in amorphous barium germanate," Journal of Non-Crystalline Solids, vol. 320, no. 1-3, pp. 133142, 2003.

[69] A. Kajinami, T. Kotake, S. Deki, and S. Kohara, "The structural analysis of manganese borate glass by high-energy X-ray diffraction measurement," Nuclear Instruments and Methods in Physics Research B, vol. 199, pp. 34-37, 2003.

[70] M. Fábián, T. Proffen, U. Ruett, E. Veress, and E. Sváb, "Uranium surroundings in borosilicate glass from neutron and X-ray diffraction and RMC modelling," Journal of Physics Condensed Matter, vol. 22, no. 40, Article ID 404206, 2010.

[71] S. Le Roux, S. Martin, R. Christensen, Y. Ren, and V. Petkov, "Three-dimensional structure of multicomponent $\left(\mathrm{Na}_{2} \mathrm{O}\right) 0.35\left[\left(\mathrm{P}_{2} \mathrm{O}_{5}\right) 1-\mathrm{x}\left(\mathrm{B}_{2} \mathrm{O}_{3}\right) \mathrm{x}\right] 0.65$ glasses by high-energy 
X-ray diffraction and constrained reverse Monte Carlo simulations," Journal of Physics Condensed Matter, vol. 23, no. 3, Article ID 035403, 2011.

[72] C. J. Benmore, J. K. R. Weber, S. Sampath, J. Siewenie, J. Urquidi, and J. A. Tangeman, "A neutron and X-ray diffraction study of calcium aluminate glasses," Journal of Physics Condensed Matter, vol. 15, no. 31, pp. S2413-S2423, 2003.

[73] Q. Mei, C. J. Benmore, J. Siewenie, J. K. R. Weber, and M. Wilding, "Diffraction study of calcium aluminate glasses and melts: I. High energy X-ray and neutron diffraction on glasses around the eutectic composition," Journal of Physics Condensed Matter, vol. 20, no. 24, Article ID 245106, 2008.

[74] J. Du, C. J. Benmore, R. Corrales, R. T. Hart, and J. K. R. Weber, "A molecular dynamics simulation interpretation of neutron and $\mathrm{X}$-ray diffraction measurements on single phase $\mathrm{Y}_{2} \mathrm{O}_{3}-\mathrm{Al}_{2} \mathrm{O}_{3}$ glasses," Journal of Physics Condensed Matter, vol. 21, no. 20, Article ID 205102, 2009.

[75] R. Weber, S. Sen, R. E. Youngman, R. T. Hart, and C. J. Benmore, "Structure of high alumina content $\mathrm{Al}_{2} \mathrm{O}_{3}-\mathrm{SiO}_{2}$ composition glasses," Journal of Physical Chemistry B, vol. 112, no. 51, pp. 16726-16733, 2008.

[76] N. Sadiki, L. Hennet, P. Florian, Y. Vaills, D. Massiot, and J. P. Coutures, "Crystallization and structural approaches of rare earths aluminosilicate glasses $(\mathrm{Ln}=\mathrm{La}, \mathrm{Y}, \mathrm{Sc})$," Materiaux \& Techniques, vol. 98, no. 6-7, p. 409, 2010.

[77] U. Hoppe, E. Metwalli, R. K. Brow, and J. Neuefeind, "High-energy X-ray diffraction study of La co-ordination in lanthanum phosphate glasses," Journal of Non-Crystalline Solids, vol. 297, no. 2-3, pp. 263-274, 2002.

[78] U. Hoppe, D. Ilieva, and J. Neuefeind, "The structure of gallium phosphate glasses by high-energy X-ray diffraction," Zeitschrift fur Naturforschung A, vol. 57, no. 8, pp. 709-715, 2002.

[79] U. Hoppe, M. Karabulut, E. Metwalli, R. K. Brow, and P. Jóvári, "The $\mathrm{Fe}-\mathrm{O}$ coordination in iron phosphate glasses by X-ray diffraction with high energy photons," Journal of Physics Condensed Matter, vol. 15, no. 36, pp. 6143-6153, 2003.

[80] U. Hoppe, R. Kranold, A. Ghosh, C. Landron, J. Neuefeind, and P. Jóvári, "Environments of lead cations in oxide glasses probed by X-ray diffraction," Journal of Non-Crystalline Solids, vol. 328, no. 1-3, pp. 146-156, 2003.

[81] U. Hoppe, Y. Dimitriev, and P. Jóvari, "Structure of zinc phosphate glasses of 75 and 80 mole $\% \mathrm{ZnO}$ content studied by X-ray diffraction and reverse Monte Carlo simulations," Zeitschrift fur Naturforschung A, vol. 60, no. 7, pp. 517-526, 2005.

[82] U. Hoppe, R. K. Brow, B. C. Tischendorf et al., "Structure of titanophosphate glasses studied by X-ray and neutron diffraction," Journal of Non-Crystalline Solids, vol. 353, no. 18-21, pp. 1802-1807, 2007.

[83] H. Schlenz, F. Reinauer, R. Glaum, J. Neuefeind, B. Brendebach, and J. Hormes, "High-energy X-ray diffraction study of Ni-doped sodium metaphosphate glasses," Journal of NonCrystalline Solids, vol. 351, no. 12-13, pp. 1014-1019, 2005.

[84] D. Qiu, P. Guerry, I. Ahmed et al., "A high-energy Xray diffraction, $31 \mathrm{P}$ and $11 \mathrm{~B}$ solid-state NMR study of the structure of aged sodium borophosphate glasses," Materials Chemistry and Physics, vol. 111, no. 2-3, pp. 455-462, 2008.

[85] E. Bychkov, C. J. Benmore, and D. L. Price, "Compositional changes of the first sharp diffraction peak in binary selenide glasses," Physical Review B, vol. 72, no. 17, pp. 1-4, 2005.
[86] Y. Murakami, T. Usuki, M. Sakurai, and S. Kohara, "Intermediate-range structure of amorphous $\mathrm{GeSe}_{2}$ alloy," Materials Science and Engineering A, vol. 448-451, pp. 544-547, 2007.

[87] T. Usuki, K. Nakajima, T. Furukawa et al., "Structure of fast ion conducting $\mathrm{AgI}-\mathrm{As}_{2} \mathrm{Se}_{3}$ glasses," Journal of NonCrystalline Solids, vol. 353, no. 32-40, pp. 3040-3044, 2007.

[88] R. Suenaga, Y. Kawakita, S. Nakashima, S. Tahara, S. Kohara, and S. Takeda, "Static structure of superionic conducting glass of Ag-Ge-Se system," Journal of Physics, vol. 98, no. 1, Article ID 012021, 2008.

[89] M. T. M. Shatnawi, C. L. Farrow, P. Chen et al., "Search for a structural response to the intermediate phase in Gex Se1-x glasses," Physical Review B, vol. 77, no. 9, Article ID 094134, 2008.

[90] V. Petkov and D. Le Messurier, "Atomic-scale structure of $\mathrm{GeSe}_{2}$ glass revisited: a continuous or broken network of Ge(Se1/2)4 tetrahedra?" Journal of Physics Condensed Matter, vol. 22, no. 11, Article ID 115402, 2010.

[91] I. Kaban, P. Jóvári, T. Petkova et al., "Structure of $\mathrm{GeSe}_{4}$-In and $\mathrm{GeSe}_{5}$-In glasses," Journal of Physics Condensed Matter, vol. 22, no. 40, Article ID 404205, 2010.

[92] E. Bychkov, M. Miloshova, D. L. Price, C. J. Benmore, and A. Lorriaux, "Short, intermediate and mesoscopic range order in sulfur-rich binary glasses," Journal of Non-Crystalline Solids, vol. 352, no. 1, pp. 63-70, 2006.

[93] F. Hindle, M. Miloshova, E. Bychkov, C. J. Benmore, and A. C. Hannon, "Structural analysis of ${ }_{x} \mathrm{CsCl}_{(1-x)} \mathrm{Ga}_{2} \mathrm{~S}_{3}$ glasses," Journal of Non-Crystalline Solids, vol. 354, no. 2-9, pp. 134137, 2008.

[94] D. L. Messurier, V. Petkov, S. W. Martin, Y. Kim, and Y. Ren, "Three-dimensional structure of fast ion conducting $0.5 \mathrm{Li}_{2} \mathrm{~S}$ $+0.5\left[(1-\mathrm{x}) \mathrm{GeS}_{2}+\mathrm{xGeO}_{2}\right]$ glasses from high-energy X-ray diffraction and reverse Monte Carlo simulations," Journal of Non-Crystalline Solids, vol. 355, no. 7, pp. 430-437, 2009.

[95] I. Kaban, P. Jóvri, T. Wagner et al., "Atomic structure of $\mathrm{As}_{2} \mathrm{~S}_{3}$-Ag chalcogenide glasses," Journal of Physics Condensed Matter, vol. 21, no. 39, Article ID 395801, 2009.

[96] S. S. Uzun, S. Sen, C. J. Benmore, and B. G. Aitken, "A combined neutron and X-ray diffraction study of shortand intermediate-range structural characteristics of Ge-As sulfide glasses," Journal of Physics Condensed Matter, vol. 20, no. 33, Article ID 335105, 2008.

[97] S. S. Uzun, S. Sen, C. J. Benmore, and B. G. Aitken, "Compositional variation of short- and intermediate-range structure and chemical order in Ge-As sulfide glasses: a neutron diffraction study," Journal of Physical Chemistry C, vol. 112, no. 18, pp. 7263-7269, 2008.

[98] S. Soyer-Uzun, C. J. Benmore, J. E. Siewenie, and S. Sen, "The nature of intermediate-range order in Ge-As-S glasses: results from reverse Monte Carlo modeling," Journal of Physics Condensed Matter, vol. 22, no. 11, Article ID 115404, 2010.

[99] J. C. McLaughlin, S. L. Tagg, and J. W. Zwanziger, "The structure of alkali tellurite glasses," Journal of Physical Chemistry B, vol. 105, no. 1, pp. 67-75, 2001.

[100] U. Hoppe, E. Yousef, C. Rüssel, J. Neuefeind, and A. C. Hannon, "Structure of zinc and niobium tellurite glasses by neutron and X-ray diffraction," Journal of Physics Condensed Matter, vol. 16, no. 9, pp. 1645-1663, 2004.

[101] U. Hoppe, I. Gugov, H. Bürger, P. Jóvári, and A. C. Hannon, "Structure of tellurite glasses-effects of $\mathrm{K}_{2} \mathrm{O}$ or $\mathrm{P}_{2} \mathrm{O}_{5}$ additions studied by diffraction," Journal of Physics Condensed Matter, vol. 17, no. 15, pp. 2365-2386, 2005. 
[102] M. Takata, Y. Tanaka, K. Kato et al., "Structure and the mechanism of rapid phase change in amorphous Ge 2Sb2Te2," Physics and Chemistry of Glasses B, vol. 50, no. 3, pp. 205211, 2009.

[103] S. Sen, S. SoyerUzun, C. J. Benmore, and B. G. Aitken, "Structure, topology and chemical order in Ge-As-Te glasses: a high-energy X-ray diffraction study," Journal of Physics Condensed Matter, vol. 22, no. 40, Article ID 405401, 2010.

[104] J. Kalikka, J. Akola, R. O. Jones, S. Kohara, and T. Usuki, "Amorphous Ge15Te85: density functional, high-energy Xray and neutron diffraction study," Journal of PhysicsCondensed Matter, vol. 24, no. 1, p. 015802, 2012.

[105] E. Bychkov, D. L. Price, C. J. Benmore, and A. C. Hannon, "Ion transport regimes in chalcogenide and chalcohalide glasses: from the host to the cation-related network connectivity," Solid State Ionics, vol. 154-155, pp. 349-359, 2002.

[106] T. Usuki, K. Nakajima, T. Furukawa et al., "Glass network structure in noble metal chalcohalide glasses solid state ionics," in The Science and Technology of Ions in Motion. 9th Asian Conference on Solid State Ionics, Cheju Isl., South Korea, B. V. R. . Chowdari, H. L. Yoo, G. M. Choi, and J. H. Lee, Eds., pp. 835-842, 2004.

[107] T. Usuki, K. Nakajima, T. Furukawa et al., "Ionic conduction pathways in noble metal chalcohalide glasses," Solid State Ionics, vol. 177, no. 26-32, pp. 2581-2584, 2006.

[108] E. Matsubara, T. Ichitsubo, J. Saida, S. Kohara, and H. Ohsumi, "Structural study of Zr-based metallic glasses," Journal of Alloys and Compounds, vol. 434-435, pp. 119-120, 2007.

[109] Z. W. Zhu, S. J. Zheng, H. F. Zhang et al., "Plasticity of bulk metallic glasses improved by controlling the solidification condition," Journal of Materials Research, vol. 23, no. 4, pp. 941-948, 2008.

[110] J. W. Qiao, E. W. Huang, F. Jiang et al., "Resolving ensembled microstructural information of bulk-metallic-glass- matrix composites using synchrotron X-ray diffraction," Applied Physics Letters, vol. 97, no. 17, Article ID 171910, 2010.

[111] D. M. Liu, Z. H. Nie, Y. Ren et al., "Structural transitions and magnetic properties of $\mathrm{Ni}_{50} \mathrm{Mn}_{36}$.7 In 13.3 particles with amorphous-like phase," Metallurgical and Materials Transactions A, pp. 1-9, 2011.

[112] M. Yan, S. Kohara, J. Q. Wang, K. Nogita, G. B. Schaffer, and M. Qian, "The influence of topological structure on bulk glass formation inal-based metallic glasses," Scripta Materialia, vol. 65, no. 9, pp. 755-758, 2011.

[113] A. Mizuno, S. Matsumura, M. Watanabe, S. Kohara, and M. Takata, "High-energy X-ray diffraction study of liquid structure of metallic glass-forming Zr70Cu30 alloy," Materials Transactions, vol. 46, no. 12, pp. 2799-2802, 2005.

[114] A. Mizuno, T. Kaneko, S. Matsumura, M. Watanabe, S. Kohara, and M. Takata, "Structure of $\mathrm{Zr}-\mathrm{Cu}$ and $\mathrm{Zr}-\mathrm{Ni}$ liquid alloys studied by high-energy X-ray diffraction," Materials Science Forum, vol. 561-565, no. 2, pp. 1349-1352, 2007.

[115] H. Fujii, S. Tahara, Y. Kato et al., "Structural properties of liquid $\mathrm{Au}-\mathrm{Si}$ and $\mathrm{Au}-\mathrm{Ge}$ alloys with deep eutectic region," Journal of Non-Crystalline Solids, vol. 353, no. 18-21, pp. 2094-2098, 2007.

[116] S. Takeda, H. Fujii, Y. Kawakita et al., "Structure of eutectic alloys of Au with Si and Ge," Journal of Alloys and Compounds, vol. 452, no. 1, pp. 149-153, 2008.

[117] Y. E. Kalay, L. S. Chumbley, M. J. Kramer, and I. E. Anderson, "Local structure in marginal glass forming Al-Sm alloy," Intermetallics, vol. 18, no. 8, pp. 1676-1682, 2010.
[118] D. Ma, A. D. Stoica, L. Yang et al., "Nearest-neighbor coordination and chemical ordering in multicomponent bulk metallic glasses," Applied Physics Letters, vol. 90, no. 21, Article ID 211908, 2007.

[119] K. Georgarakis, A. R. Yavari, D. V. Louzguine, G. Vaughan, and W. J. Botta, "Atomic structure of bulk metallic glasses and their supercooled liquid states probed by high-energy synchrotron light," Comptes Rendus Physique, vol. 13, no. 3, pp. 218-226, 2012.

[120] M. Watanabe, A. Mizuno, T. Akimoto, and S. Kohara, "Insitu observation of solidification of bulk metallic glass forming alloys from supercooled liquid by using high energy X-ray diffraction combined with levitation techniques," Materials Science Forum, vol. 638-642, pp. 1677-1682, 2010.

[121] N. Mattern, U. Kühn, J. Sakowski, J. Neuefeind, and J. Eckert, "Structure of $\mathrm{Zr}_{52} \mathrm{Ti}_{5} \mathrm{Cu}_{18} \mathrm{Ni} 15 \mathrm{Al} 10$ bulk metallic glass at elevated temperatures," Materials Science Forum, vol. 443444, pp. 227-230, 2004.

[122] N. Mattern, M. Stoica, G. Vaughan, and J. Eckert, "Thermal behaviour of $\mathrm{Pd}_{40} \mathrm{Cu}_{30} \mathrm{Ni}_{10} \mathrm{P}_{20}$ bulk metallic glass," Acta Materialia, vol. 60, no. 2, pp. 517-524, 2012.

[123] T. Nasu, M. Sasaki, T. Usuki et al., "Direct observation of radial distribution change during tensile deformation of metallic glass by high energy X-ray diffraction method," Journal of Alloys and Compounds, vol. 483, no. 1-2, pp. 589592, 2009.

[124] W. Dmowski, Y. Yokoyama, A. Chuang et al., "Structural rejuvenation in a bulk metallic glass induced by severe plastic deformation," Acta Materialia, vol. 58, no. 2, pp. 429-438, 2010.

[125] D. Qu, Liss, K. -D et al., "On the atomic anisotropy of thermal expansion in bulk metallic glass," Advanced Engineering Materials, vol. 13, no. 9, pp. 861-864, 2011.

[126] L. L. Ma, L. Wang, Y. F. Xue et al., "An in situ high-energy $\mathrm{X}$-ray diffraction study of micromechanical behavior of $\mathrm{Zr}$ based metallic glass reinforced porous W matrix composite," Materials Science and Engineering A, vol. 530, pp. 344-348, 2011.

[127] Y. J. Sun, D. D. Qu, Y. J. Huang et al., "Zr-Cu-Ni-Al bulk metallic glasses with superhigh glass-forming ability," Acta Materialia, vol. 57, no. 4, pp. 1290-1299, 2009.

[128] M. I. Mendelev, M. J. Kramer, R. T. Ott et al., "Experimental and computer simulation determination of the structural changes occurring through the liquid-glass transition in $\mathrm{Cu}-$ Zr alloys," Philosophical Magazine, vol. 90, no. 29, pp. 37953815, 2010.

[129] Y. L. Sun, D. D. Qu, Y. J. Sun, K. D. Liss, and J. Shen, "Inhomogeneous structure and glass-forming ability in $\mathrm{Zr}$ based bulk metallic glasses," Journal of Non-Crystalline Solids, vol. 356, no. 1, pp. 39-45, 2010.

[130] M. Ghafari, S. Kohara, H. Hahn et al., "Structural investigations of interfaces in $\mathrm{Fe}_{90} \mathrm{Sc}_{10}$ nanoglasses using high-energy X-ray diffraction," Applied Physics Letters, vol. 100, no. 13, 133111 pages, 2012.

[131] S. Takeda, H. Fujii, Y. Kawakita et al., "Structure of liquid AuSi alloys around the eutectic region," Materials Science and Engineering A, vol. 448-451, pp. 590-593, 2007.

[132] N. A. Mauro, V. Wessels, J. C. Bendert et al., "Short- and medium-range order in $\mathrm{Zr}_{80} \mathrm{Pt}_{20}$ liquids," Physical Review B, vol. 83, no. 18, Article ID 184109, 2011.

[133] A. Zeidler, P. S. Salmon, R. A. Martin et al., "Structure of liquid and glassy $\mathrm{ZnCl}_{2}$," Physical Review B, vol. 82, no. 10, Article ID 104208, 2010. 
[134] S. Tahara, H. Ueno, K. Ohara et al., "Medium-range correlation of $\mathrm{Ag}$ ions in superionic melts of $\mathrm{Ag}_{2} \mathrm{Se}$ and $\mathrm{AgI}$ by reverse Monte Carlo structural modelling-connectivity and void distribution," Journal of Physics Condensed Matter, vol. 23, no. 23, Article ID 235102, 2011.

[135] Y. Kawakita, S. Fujita, S. Kohara et al., "Structure and electron-ion correlation of liquid germanium," Nuclear Instruments and Methods in Physics Research B, vol. 238, no. 1-4, pp. 129-133, 2005.

[136] D. Le Coq, A. Bytchkov, V. Honkimäki, B. Beuneu, and E. Bychkov, "Neutron and X-ray diffraction studies of $\mathrm{TeCl}_{4}$ and $\mathrm{TeBr}_{4}$ liquids," Journal of Non-Crystalline Solids, vol. 354, no. 2-9, pp. 259-262, 2008.

[137] J. Akola, R. O. Jones, S. Kohara, T. Usuki, and E. Bychkov, "Density variations in liquid tellurium: roles of rings, chains, and cavities," Physical Review B, vol. 81, no. 9, Article ID 094202, 2010.

[138] J. W. E. Drewitt, S. Jahn, V. Cristiglio et al., "The structure of liquid calcium aluminates as investigated using neutron and high energy X-ray diffraction in combination with molecular dynamics simulation methods," Journal of Physics Condensed Matter, vol. 23, no. 15, Article ID 155101, 2011.

[139] Q. Mei, C. J. Benmore, J. K. R. Weber, M. Wilding, J. Kim, and J. Rix, "Diffraction study of calcium aluminate glasses and melts: II. High energy X-ray diffraction on melts," Journal of Physics Condensed Matter, vol. 20, no. 24, Article ID 245107, 2008.

[140] M. C. Wilding, C. J. Benmore, and J. K. R. Weber, "In situ diffraction studies of magnesium silicate liquids," Journal of Materials Science, vol. 43, no. 14, pp. 4707-4713, 2008.

[141] M. C. Wilding, C. J. Benmore, and J. K. R. Weber, "Highenergy X-ray diffraction from aluminosilicate liquids," Journal of Physical Chemistry B, vol. 114, no. 17, pp. 5742-5746, 2010.

[142] J. Neuefeind, C. J. Benmore, B. Tomberli, and P. A. Egelstaff, "Experimental determination of the electron density of liquid $\mathrm{H}_{2} \mathrm{O}$ and $\mathrm{D}_{2} \mathrm{O}$," Journal of Physics Condensed Matter, vol. 14, no. 23, pp. L429-L433, 2002.

[143] J. Neuefeind, C. J. Benmore, J. K. R. Weber, and D. Paschek, "More accurate X-ray scattering data of deeply supercooled bulk liquid water," Molecular Physics, vol. 109, no. 2, pp. 279288, 2011.

[144] S. E. McLain, C. J. Benmore, and J. F. C. Turner, "The structure of liquid fluorosulfuric acid investigated by neutron diffraction," Journal of Chemical Physics, vol. 117, no. 8, pp. 3816-3821, 2002.

[145] K. Matsumoto, R. Hagiwara, Y. Ito, S. Kohara, and K. Suzuya, "Structural analysis of 1-ethyl-3-methylimidazolium bifluoride melt," Nuclear Instruments and Methods in Physics Research B, vol. 199, pp. 29-33, 2003.

[146] S. E. McLain, C. J. Benmore, J. E. Siewenie, J. Urquidi, and J. F. C. Turner, "On the structure of liquid hydrogen fluoride," Angewandte Chemie, vol. 43, no. 15, pp. 1952-1955, 2004.

[147] S. E. McLain, C. J. Benmore, J. E. Siewenie, J. J. Molaison, and J. F. C. Turner, "On the variation of the structure of liquid deuterium fluoride with temperature," Journal of Chemical Physics, vol. 121, no. 13, pp. 6448-6455, 2004.

[148] Y. Shodai, S. Kohara, Y. Ohishi, M. Inaba, and A. Tasaka, "Anionic species $(\mathrm{FH}) \mathrm{xF}$ - in room-temperature molten fluorides (CH3)4NF-mHF," Journal of Physical Chemistry A, vol. 108, no. 7, pp. 1127-1132, 2004.

[149] S. E. McLain, A. K. Soper, J. J. Molaison et al., "On the structure of liquid antimony pentafluoride," Journal of Molecular Liquids, vol. 131-132, pp. 239-245, 2007.
[150] S. Kohara, M. Takata, K. Matsumoto et al., "Very strong hydrogen bonds in a bent chain structure of fluorohydrogenate anions in liquid Cs (FH)2.3 F," Journal of Chemical Physics, vol. 129, no. 1, Article ID 014512, 2008.

[151] S. Kohara, R. Hagiwara, K. Matsumoto, Y. Ito, A. Kajinami, and K. Suzuya, "High-energy X-ray diffraction studies of alkylimidazolium fluorohydrogenate room temperature molten salts at SPring-8 High-energy X-ray diffraction beamline BL104B2," in Proceedings of the 13th International Symposium on Molten Salts, Molten Salts XIII, P. C. Trulove, H. C. Delong, R. A. Mantz, G. R. Stafford, and M. Matsunaga, Eds., Electrochemical Society Series, p. 1047, Philadelphia, $\mathrm{Pa}, \mathrm{USA}, 2002$.

[152] R. Hagiwara, K. Matsumoto, T. Tsuda et al., “The structures of alkylimidazolium fluorohydrogenate molten salts studied by high-energy X-ray diffraction," Journal of Non-Crystalline Solids, vol. 312-314, pp. 414-418, 2002.

[153] K. Fujii, S. Seki, S. Fukuda et al., "Liquid structure and conformation of a low-viscosity ionic liquid, N-methyl-Npropyl-pyrrolidinium bis(fluorosulfonyl) imide studied by high-energy X-ray scattering," Journal of Molecular Liquids, vol. 143, no. 1, pp. 64-69, 2008.

[154] Y. Umebayashi, H. Hamano, S. Tsuzuki et al., "Dependence of the conformational isomerism in 1-n-butyl-3methylimidazolium ionic liquids on the nature of the halide anion," Journal of Physical Chemistry B, vol. 114, no. 36, pp. 11715-11724, 2010.

[155] B. Aoun, A. Goldbach, S. Kohara, J. F. Wax, M. A. González, and M. L. Saboungi, "Structure of a prototypic ionic liquid: ethyl-methylimidazolium bromide," Journal of Physical Chemistry B, vol. 114, no. 39, pp. 12623-12628, 2010.

[156] B. Aoun, A. Goldbach, M. A. González, S. Kohara, D. L. Price, and M. L. Saboungi, "Nanoscale heterogeneity in alkyl-methylimidazolium bromide ionic liquids," Journal of Chemical Physics, vol. 134, no. 10, Article ID 104509, 2011.

[157] T. Isogai, T. Nakai, H. Inoue et al., "Analysis of cationic structure in some room-temperature molten fluorides and dependence of their ionic conductivity and viscosity on hydrofluoric acid concentration," Journal of Physical Chemistry B, vol. 115, no. 31, pp. 9593-9603, 2011.

[158] K. Fujii, R. Kanzaki, T. Takamuku et al., "Experimental evidences for molecular origin of low-q peak in neutron/X-ray scattering of 1-alkyl-3-methylimidazolium bis(trifluoromethanesulfonyl)amide ionic liquids," Journal of Chemical Physics, vol. 135, no. 24, p. 244502, 2011.

[159] C. S. Santos, N. S. Murthy, G. A. Baker, and E. W. Castner Jr, "Communication: $\mathrm{X}$-ray scattering from ionic liquids with pyrrolidinium cations," Journal of Chemical Physics, vol. 134, no. 12, Article ID 121101, 2011.

[160] C. S. Santos, H. V. R. Annapureddy, N. S. Murthy, H. K. Kashyap, E. W. Castner Jr, and C. J. Margulis, "Temperature-dependent structure of methyltributylammonium bis(trifluoromethylsulfonyl)amide: $\mathrm{X}$ ray scattering and simulations," Journal of Chemical Physics, vol. 134, no. 6, Article ID 064501, 2011.

[161] Y. Umebayashi, H. Harnano, S. Seki et al., "Liquid structure of and $\mathrm{Li}^{+}$ion solvation inbis(trifluoromethanesulfonyl)amide based ionic liquids composed of 1-ethyl3-methylimidazolium and n-methyl-n-propylpyrrolidinium cations," Journal of Physical Chemistry B, vol. 115, no. 42, p. 12179, 2011.

[162] X. Song, H. Hamano, B. Minofar et al., "Structural heterogeneity and unique distorted hydrogen bonding in primary ammonium nitrate ionic liquids studied by high-energy 
X-ray diffraction experiments and MD simulations," Journal of Physical Chemistry B, vol. 116, no. 9, p. 2801, 2012.

[163] C. S. Santos, H. V. R. Annapureddy, N. S. Murthy, H. K. Kashyap, E. W. Castner Jr, and C. J. Margulis, "Temperature-dependent structure of methyltributylammonium bis(trifluoromethylsulfonyl)amide: $\mathrm{X}$ ray scattering and simulations," Journal of Chemical Physics, vol. 134, no. 6, Article ID 064501, 2011.

[164] L. Soderholm, S. Skanthakumar, and J. Neuefeind, "Determination of actinide speciation in solution using high-energy X-ray scattering," Analytical and Bioanalytical Chemistry, vol. 383, no. 1, pp. 48-55, 2005.

[165] S. Skanthakumar, M. R. Antonio, R. E. Wilson, and L. Soderholm, "The curium aqua ion," Inorganic Chemistry, vol. 46, no. 9, pp. 3485-3491, 2007.

[166] L. Soderholm, P. M. Almond, S. Skanthakumar, R. E. Wilson, and P. C. Burns, "The structure of the plutonium oxide nanocluster $\left[\mathrm{Pu}_{38} \mathrm{O}{ }_{56} \mathrm{Cl}_{54}\left(\mathrm{H}_{2} \mathrm{O}\right)_{8}\right]_{14}$," Angewandte Chemie, vol. 47, no. 2, pp. 298-302, 2008.

[167] L. Soderholm, S. Skanthakumar, D. Gorman-Lewis, M. P. Jensen, and K. L. Nagy, "Characterizing solution and solid-phase amorphous uranyl silicates," Geochimica et Cosmochimica Acta, vol. 72, no. 1, pp. 140-150, 2008.

[168] L. Soderholm, S. Skanthakumar, and R. E. Wilson, "Structures and energetics of erbium chloride complexes in aqueous solution," Journal of Physical Chemistry A, vol. 113, no. 22, pp. 6391-6397, 2009.

[169] J. F. C. Turner, S. E. McLain, T. H. Free, C. J. Benmore, K. W. Herwig, and J. E. Siewenie, "Sample containment for neutron and high-energy X-ray scattering studies of hydrogen fluoride and related molecular species," Review of Scientific Instruments, vol. 74, no. 10, pp. 4410-4417, 2003.

[170] R. T. Hart, C. J. Benmore, J. Neuefeind, S. Kohara, B. Tomberli, and P. A. Egelstaff, "Temperature dependence of isotopic quantum effects in water," Physical Review Letters, vol. 94, no. 4, Article ID 047801, 2005.

[171] R. T. Hart, Q. Mei, C. J. Benmore et al., "Isotope quantum effects in water around the freezing point," Journal of Chemical Physics, vol. 124, no. 13, Article ID 134505, 2006.

[172] A. K. Soper and C. J. Benmore, "Quantum differences between heavy and light water," Physical Review Letters, vol. 101, no. 6, Article ID 065502, 2008.

[173] C. J. Benmore, B. Tomberli, P. A. Egelstaff, and J. Neuefeind, "Quantum effects in the structure of liquid benzene at room temperature," Molecular Physics, vol. 99, no. 10, pp. 787-794, 2001.

[174] C. J. Benmore, B. Tomberli, J. Neuefeind, and P. A. Egelstaff, "Isotopic quantum correction to liquid methanol at $-30 \circ \mathrm{C}$," Applied Physics A, vol. 74, no. II, pp. S1670-S1672, 2002.

[175] B. Tomberli, C. J. Benmore, J. Neuefeind, and P. A. Egelstaff, "Isotopic quantum effects in the structure of liquid ethanol," Canadian Journal of Physics, vol. 80, no. 9, pp. 1059-1068, 2002.

[176] S. Sampath, K. M. Lantzky, C. J. Benmore et al., "Structural quantum isotope effects in amorphous beryllium hydride," Journal of Chemical Physics, vol. 119, no. 23, pp. 1249912502, 2003.

[177] J. Urquidi, C. J. Benmore, J. Neuefeind et al., "Isotopic quantum effects on the structure of low density amorphous ice," Journal of Physics Condensed Matter, vol. 15, no. 22, pp. 3657-3664, 2003.

[178] Y. S. Badyal, D. L. Price, M. L. Saboungi, D. R. Haeffner, and S. D. Shastri, "Quantum effects on the structure of water at constant temperature and constant atomic density," Journal of Chemical Physics, vol. 116, no. 24, pp. 10833-10837, 2002.

[179] C. J. Benmore and P. J. M. Monteiro, "The structure of alkali silicate gel by total scattering methods," Cement and Concrete Research, vol. 40, no. 6, pp. 892-897, 2010.

[180] L. B. Skinner, S. R. Chae, C. J. Benmore, H. R. Wenk, and P. J. M. Monteiro, "Nanostructure of calcium silicate hydrates in cements," Physical Review Letters, vol. 104, no. 19, Article ID 195502, 2010.

[181] C. Meral, C. J. Benmore, and P. J. M. Monteiro, "The study of disorder and nanocrystallinity in C-S-H, supplementary cementitious materials and geopolymers using pair distribution function analysis," Cement and Concrete Research, vol. 41, no. 7, pp. 696-710, 2011.

[182] S. Soyer-Uzun, C. J. Benmore, H.-R. Wenk, and P. J. M. Monteiro, "Investigation of compositional evolution of structure of calcium silicate hydrates $(\mathrm{C}-\mathrm{S}-\mathrm{H})$ by total scattering," Journal of American Ceramic Society, vol. 95, no. 2, pp. 793-798, 2012.

[183] V. FitzGerald, K. O. Drake, J. R. Jones et al., "In situ high-energy X-ray diffraction study of a bioactive calcium silicate foam immersed in simulated body fluid," Journal of Synchrotron Radiation, vol. 14, no. 6, pp. 492-499, 2007.

[184] T. Wakihara, S. Kohara, G. Sankar et al., "A new approach to the determination of atomic-architecture of amorphous zeolite precursors by high-energy X-ray diffraction technique," Physical Chemistry Chemical Physics, vol. 8, no. 2, pp. 224227, 2006.

[185] K. Sato, T. Wakihara, S. Kohara et al., "Effect of the atomic arrangement of amorphized zeolite on the recrystallization behavior to crystalline zeolite," Nippon Seramikkusu Kyokai Gakujutsu Ronbunshi/Journal of the Ceramic Society of Japan, vol. 119, no. 1391, pp. 605-608, 2011.

[186] C. J. Benmore, T. Izdebski, and J. L. Yarger, "Total X-ray scattering of spider dragline silk," Physical Review Letters, vol. 108, no. 17, p. 178102, 2012.

[187] C. P. Chuang, J. H. Huang, W. Dmowski et al., "The effect of hydrogen charging on Ln-based amorphous materials," Applied Physics Letters, vol. 95, no. 24, Article ID 241901, 2009.

[188] C. A. Hoel, S. Xie, C. Benmore, C. D. Malliakas, J. F. Gaillard, and K. R. Poeppelmeier, "Evidence for tetrahedral zinc in amorphous In2-2xZn $\mathrm{xSnxO}_{3}$ (a-ZITO)," Zeitschrift fur Anorganische und Allgemeine Chemie, vol. 637, no. 7-8, pp. 885-894, 2011.

[189] P. W. Bridgman and I. Šimon, "Effects of very high pressures on glass," Journal of Applied Physics, vol. 24, no. 4, pp. 405413, 1953.

[190] S. Sampath, C. J. Benmore, K. M. Lantzky et al., "Intermediate-range order in permanently densified $\mathrm{GeO}_{2}$ glass," Physical Review Letters, vol. 90, no. 11, pp. 115502/1115502/4, 2003.

[191] Q. Mei, P. V. Teredesai, C. J. Benmore et al., "The structure of permanently densified $\mathrm{GeSe}_{2}$ glasses," Physics and Chemistry of Glasses, vol. 46, no. 4, pp. 483-486, 2005.

[192] Q. Mei, C. J. Benmore, S. Sampath et al., "The structure of permanently densified $\mathrm{CaAl}_{2} \mathrm{O}_{4}$ glass," Journal of Physics and Chemistry of Solids, vol. 67, no. 9-10, pp. 2106-2110, 2006.

[193] Q. Mei, R. T. Hart, C. J. Benmore, S. Amin, K. Leinenweber, and J. L. Yarger, "The structure of densified $\mathrm{As}_{2} \mathrm{O}_{3}$ glasses," Journal of Non-Crystalline Solids, vol. 353, no. 18-21, pp. 1755-1758, 2007. 
[194] S. Soyer Uzun, S. J. Gaudio, S. Sen et al., "In situ highpressure X-ray diffraction study of densification of a molecular chalcogenide glass," Journal of Physics and Chemistry of Solids, vol. 69, no. 9, pp. 2336-2340, 2008.

[195] Q. Mei, C. J. Benmore, R. T. Hart et al., "Topological changes in glassy $\mathrm{GeSe}_{2}$ at pressures up to $9.3 \mathrm{GPa}$ determined by high-energy X-ray and neutron diffraction measurements," Physical Review B, vol. 74, no. 1, Article ID 014203, 2006.

[196] Q. Mei, C. J. Benmore, E. Soignard, S. Amin, and J. L. Yarger, "Analysis of high-energy X-ray diffraction data at high pressure: the case of vitreous $\mathrm{As}_{2} \mathrm{O}_{3}$ at $32 \mathrm{GPa}$," Journal of Physics-Condensed Matter, vol. 19, no. 41, p. 415103, 2007.

[197] E. Soignard, S. A. Amin, Q. Mei, C. J. Benmore, and J. L. Yarger, "High-pressure behavior of $\mathrm{As}_{2} \mathrm{O}_{3}$ : amorphousamorphous and crystalline-amorphous transitions," Physical Review B, vol. 77, no. 14, Article ID 144113, 2008.

[198] S. M. Antao, C. J. Benmore, B. Li, L. Wang, E. Bychkov, and J. B. Parise, "Network rigidity in $\mathrm{GeSe}_{2}$ glass at high pressure," Physical Review Letters, vol. 100, no. 11, Article ID 115501, 2008.

[199] C. J. Benmore, E. Soignard, Q. Mei, S. Sen, J. B. Parise, and J. L. Yarger, "Transitions in network and molecular glasses at high pressure," in 6th International Conference on Synchrotron Radiation in Materials Science, pp. 5-8, bra, July 2008.

[200] A. Zeidler, J. W. E. Drewitt, P. S. Salmon et al., "Establishing the structure of $\mathrm{GeS}_{2}$ at high pressures and temperatures: a combined approach using X-ray and neutron diffraction," Journal of Physics Condensed Matter, vol. 21, no. 47, Article ID $474217,2009$.

[201] C. J. Benmore, E. Soignard, S. A. Amin et al., "Structural and topological changes in silica glass at pressure," Physical Review B, vol. 81, no. 5, Article ID 054105, 2010.

[202] J. B. Parise, L. Ehm, C. J. Benmore, S. M. Antao, F. M. Michel, and K. Takemura, "Quantitative measurements of phase transitions in nano- and glassy materials," Journal of Physics Conference Series, vol. 215, no. 1, p. 012021, 2010.

[203] Q. Mei, S. Sinogeikin, G. Shen, S. Amin, C. J. Benmore, and K. Ding, "High-pressure X-ray diffraction measurements on vitreous $\mathrm{GeO}_{2}$ under hydrostatic conditions," Physical Review B, vol. 81, no. 17, Article ID 174113, 2010.

[204] L. Wang, W. Yang, Y. Ding et al., "Size-dependent amorphization of nanoscale $\mathrm{Y} 2 \mathrm{O} 3$ at high pressure," Physical Review Letters, vol. 105, no. 9, Article ID 095701, 2010.

[205] C. J. Benmore, E. Soignard, M. Guthrie et al., "High pressure $\mathrm{X}$-ray diffraction measurements on $\mathrm{Mg}_{2} \mathrm{SiO}_{4}$ glass," Journal of Non-Crystalline Solids, vol. 357, no. 14, pp. 2632-2636, 2011.

[206] L. B. Skinner, C. J. Benmore, S. Antao et al., "Structural changes in vitreous $\mathrm{GeSe}_{4}$ under pressure," Journal of Physical Chemistry C, vol. 116, no. 3, p. 2212, 2012.

[207] E. N. Oelker, E. Soignard, K. A. Mckiernan, C. J. Benmore, and J. L. Yarger, "Pressure-induced crystallization of amorphous red phosphorous," Solid State Communications, vol. 152 , no. 5, pp. 390-394, 2012.

[208] E. Soignard, C. J. Benmore, and J. L. Yarger, "A perforated diamond anvil cell for high-energy X-ray diffraction of liquids and amorphous solids at high pressure," Review of Scientific Instruments, vol. 81, no. 3, Article ID 035110, 2010.

[209] A. J. Anderson, P. R. Meredith, W. A. Bassett, R. A. Mayanovic, and C. Benmore, "The design and application of a new bassett-type diamond anvil cell for spectroscopic analysis of supercritical aqueous solutions," in Proceedings of the 2nd Canada-China Joint Workshop on Supercritical WaterCooled Reactors (CCSC'10), Toronto, Canada.
[210] T. Uchino, A. Sakoh, M. Azuma et al., "Anelastic compression of nanometer-sized silica particles under high pressure: a high-energy X-ray diffraction measurement," Physical Review B, vol. 67, no. 9, Article ID 092202, pp. 922021-922024, 2003.

[211] H. F. Poulsen, J. A. Wert, J. Neuefeind, V. Honkimäki, and M. Daymond, "Measuring strain distributions in amorphous materials," Nature Materials, vol. 4, no. 1, pp. 33-36, 2005.

[212] U. K. Vempati, P. K. Valavala, M. L. Falk, J. Almer, and T. C. Hufnagel, "Length-scale dependence of elastic strain from scattering measurements in metallic glasses," Physical Review $B$, vol. 85, no. 21, p. 214201, 2012.

[213] A. R. Yavari, N. Nikolov, N. Nishiyama et al., "The glass transition of bulk metallic glasses studied by real-time diffraction in transmission using high-energy synchrotron radiation," Materials Science and Engineering A, vol. 375-377, no. 1-2, pp. 709-712, 2004.

[214] S. Matsumura, M. Watanabe, A. Mizuno, and S. Kohara, "Supercooled barium boric oxide melts: X-ray diffraction measurements and glass formation," Journal of the American Ceramic Society, vol. 90, no. 3, pp. 742-745, 2007.

[215] P. J. Chupas, X. Qiu, J. C. Hanson, P. L. Lee, C. P. Grey, and S. J. L. Billinge, "Rapid-acquisition pair distribution function (RA-PDF) analysis," Journal of Applied Crystallography, vol. 36, no. 6, pp. 1342-1347, 2003.

[216] W. J. Botta, K. Ota, K. Hajlaoui, G. Vaughan, and A. R. Yavari, "Glass transition, thermal expansion and relaxation in $\mathrm{B}_{2} \mathrm{O}_{3}$ glass measured by time-resolved X-ray diffraction," Journal of Non-Crystalline Solids, vol. 354, no. 2-9, pp. 325-327, 2008.

[217] L. Hennet, I. Pozdnyakova, A. Bytchkov et al., "Fast Xray scattering measurements on high temperature levitated liquids," Journal of Non-Crystalline Solids, vol. 354, no. 4751, pp. 5104-5107, 2008.

[218] M. C. Wilding, C. J. Benmore, J. K. R. Weber, and J. B. Parise, "In-situ measurements of the structure of supercooled oxide liquids. Synchrotron radiation in materials science conference SRMS-7," Diamond Light Source Proceedings, vol. 1, Article ID E135, 4 pages, 2011.

[219] J. K. R. Weber, C. J. Benmore, M. C. Wilding, J. Neuefeind, and J. B. Parise, "Instrumentation for structure measurements on highly non-equilibrium materials. Synchrotron radiation in materials science conference SRMS-7," Diamond Light Source Proceedings, vol. 1, Article ID E134, 2011.

[220] M. C. Wilding, C. J. Benmore, J. A. Tangeman, and S. Sampath, "Evidence of different structures in magnesium silicate liquids: coordination changes in forsterite- to enstatitecomposition glasses," Chemical Geology, vol. 213, no. 1-3, pp. 281-291, 2004

[221] Q. Mei, C. J. Benmore, and J. K. R. Weber, "Structure of liquid $\mathrm{SiO}_{2}$ : a measurement by high-energy X-ray diffraction," Physical Review Letters, vol. 98, no. 5, Article ID 057802, 2007.

[222] A. Mizuno, S. Kohara, S. Matsumura, M. Watanabe, J. K. R. Weber, and M. Takata, "Structure of glass and liquid studied with a conical nozzle levitation and diffraction technique," Materials Science Forum, vol. 539-543, no. 2, pp. 2012-2017, 2007.

[223] R. Weber, C. Benmore, M. Qiang, and M. Wilding, "In-situ $\mathrm{X}$-ray structure measurements on aerodynamically levitated high temperature liquids," in 6th International Conference on Synchrotron Radiation in Materials Science, pp. 79-83, bra, July 2008.

[224] R. Weber, Rix, J. Benmore C, Q. Mei, and M. Wilding, "Measurements of liquid structure using aerodynamic levitation, high energy X-rays and large-area X-ray detectors," in Proceedings of the American Ceramic Society glass and optical 
materials MTG. and 18th University Conference on Glass, M. Hall and C. Click, Eds., 2008.

[225] J. K. R. Weber, C. J. Benmore, G. Jennings, M. C. Wilding, and J. B. Parise, "Instrumentation for fast in-situ X-ray structure measurements on non-equilibrium liquids," Nuclear Instruments and Methods in Physics Research A, vol. 624, no. 3, pp. 728-730, 2010.

[226] M. C. Wilding, C. J. Benmore, and J. K. R. Weber, "Changes in the local environment surrounding magnesium ions in fragile $\mathrm{MgO}-\mathrm{SiO}_{2}$ liquids," $E P L$, vol. 89 , no. 2, Article ID 26005, 2010.

[227] D. L. Price, High-Temperature Levitated Materials, Cambridge University Press, 2010.

[228] L. B. Skinner, C. J. Benmore, J. K. R. Weber, and J. B. Parise, "Recent developments in research on disordered materials using high energy X-ray diffraction," in Proceedings of the Recent Advances in Structural Characterization of Materials: Scattering Methods, at the Materials Science \& Technology Meeting, pp. 348-355, Ohio, OH, USA, 2011.

[229] A. Ishikura, A. Mizuno, M. Watanabe, T. Masaki, T. Ishikawa, and S. Kohara, "Structure analysis of molten Ba-Ge alloys using electrostatic levitation technique combined with highenergy X-ray diffraction," Journal of the American Ceramic Society, vol. 90, no. 3, pp. 738-741, 2007.

[230] N. A. Mauro and K. F. Kelton, "A highly modular beamline electrostatic levitation facility, optimized for in situ highenergy X-ray scattering studies of equilibrium and supercooled liquids," Review of Scientific Instruments, vol. 82, no. 3, Article ID 035114, 2011.

[231] C. J. Benmore and J. K. R. Weber, "Amorphization of molecular liquids of pharmaceutical drugs by acoustic levitation," Physical Review, vol. X1, no. 1, p. 011004, 2011.

[232] R. Weber, C. J. Benmore, S. Tumber et al., "Acoustic levitation recent developments and emerging opportunities in biomaterials research," European Biophysics Journal, vol. 41, no. 4, pp. 397-403, 2012.

[233] C. A. Tulk, C. J. Benmore, J. Urquidi et al., "Structural studies of several distinct metastable forms of amorphous ice," Science, vol. 297, no. 5585, pp. 1320-1323, 2002.

[234] R. Roy, C. A. Tulk, C. J. Benmore et al., "Another look at water and ice," Science, vol. 299, no. 5603, pp. 44-45, 2003.

[235] G. N. Greaves, M. C. Wilding, S. Fearn et al., "Detection of first-order liquid/liquid phase transitions in yttrium oxidealuminum oxide melts," Science, vol. 322, no. 5901, pp. 566570, 2008.

[236] M. Guthrie, J. Urquidi, C. A. Tulk, C. J. Benmore, D. D. Klug, and J. Neuefeind, "Direct structural measurements of relaxation processes during transformations in amorphous ice," Physical Review B, vol. 68, no. 18, Article ID 184110, pp. 1841101-1841105, 2003.

[237] J. Urquidi, C. J. Benmore, P. A. Egelstaff et al., "A structural comparison of supercooled water and intermediate density amorphous ices," Molecular Physics, vol. 102, no. 19-20, pp. 2007-2014, 2004.

[238] M. Guthrie, C. A. Tulk, C. J. Benmore, and D. D. Klug, "A structural study of very high-density amorphous ice," Chemical Physics Letters, vol. 397, no. 4-6, pp. 335-339, 2004.

[239] J. S. Tse, D. D. Klug, M. Guthrie, C. A. Tulk, C. J. Benmore, and J. Urquidi, "Investigation of the intermediate- and highdensity forms of amorphous ice by molecular dynamics calculations and diffraction experiments," Physical Review B, vol. 71, no. 21, pp. 1-7, 2005.

[240] C. A. Tulk, R. Hart, D. D. Klug, C. J. Benmore, and J. Neuefeind, "Adding a length scale to the polyamorphic ice debate," Physical Review Letters, vol. 97, no. 11, Article ID 115503, 2006.

[241] C. A. Tulk, C. J. Benmore, D. D. Klug, and J. Neuefeind, "Comment on 'nature of the polyamorphic transition in ice under pressure," Physical Review Letters, vol. 96, no. 14, Article ID 149601, p. 1, 2006.

[242] P. F. McMillan, M. Wilson, and M. C. Wilding, "Polyamorphism in aluminate liquids," Journal of Physics Condensed Matter, vol. 15, no. 36, pp. 6105-6121, 2003.

[243] R. Weber, C. J. Benmore, J. Siewenie, J. Urquidi, and T. S. Key, "Structure and bonding in single- and two-phase aluminabased glasses," Physical Chemistry Chemical Physics, vol. 6, no. 9, pp. 2480-2483, 2004.

[244] M. C. Wilding, M. Wilson, and P. F. Mcmillan, "X-ray and neutron diffraction studies and MD simulation of atomic configurations in polyamorphic Y2O3-Al2O 3 systems," Philosophical Transactions of the Royal Society A, vol. 363, no. 1827, pp. 589-607, 2005.

[245] A. C. Barnes, L. B. Skinner, P. S. Salmon et al., "Liquid-Liquid phase transition in supercooled yttria-Alumina," Physical Review Letters, vol. 103, no. 22, Article ID 225702, 2009.

[246] G. N. Greaves, M. C. Wilding, L. Hennet et al., "Comment on 'liquid-liquid phase transition in supercooled yttriaalumina,"' Physical Review Letters, vol. 106, no. 11, Article ID 119601, 2011.

[247] G. N. Greaves, M. C. Wilding, D. Langstaff et al., "Composition and polyamorphism in supercooled yttria-alumina melts," Journal of Non-Crystalline Solids, vol. 357, no. 2, pp. 435-441, 2011.

[248] Q. Mei, P. Ghalsasi, C. J. Benmore, and J. L. Yarger, "The local structure of triphenyl phosphite studied using spallation neutron and high-energy X-ray diffraction," Journal of Physical Chemistry B, vol. 108, no. 52, pp. 20076-20082, 2004.

[249] Q. Mei, J. E. Siewenie, C. J. Benmore, P. Ghalsasi, and J. L. Yargen, "Orientational correlations in the glacial state of triphenyl phosphite," Journal of Physical Chemistry B, vol. 110, no. 20, pp. 9747-9750, 2006.

[250] C. J. Benmore, Q. Mei, J. E. Siewenie, and J. L. Yarger, "Comment on 'Microscopic structural evolution during the liquid-liquid transition in triphenyl phosphite," Journal of Physics Condensed Matter, vol. 19, no. 40, Article ID 408001, 2007.

[251] T. E. Faber and J. M. Ziman, "A theory of the electrical properties of liquid metals. III. The resistivity of binary alloys," Philosophical Magazine, vol. 11, no. 109, p. 153, 1965.

[252] D. A. Keen, "A comparison of various commonly used correlation functions for describing total scattering," Journal of Applied Crystallography, vol. 34, no. 2, pp. 172-177, 2001.

[253] C. J. Benmore, R. T. Hart, Q. Mei et al., "Intermediate range chemical ordering in amorphous and liquid water, $\mathrm{Si}$, and Ge," Physical Review B, vol. 72, no. 13, pp. 1-4, 2005.

[254] A. B. Bhatia and D. E. Thornton, "Structural aspects of the electrical resistivity of binary alloys," Physical Review B, vol. 2, no. 8, pp. 3004-3012, 1970.

[255] P. S. Salmon, "Amorphous materials: order within disorder," Nature Materials, vol. 1, no. 2, pp. 87-88, 2002.

[256] A. C. Wright, "Longer range order in single component network glasses?" Physics and Chemistry of Glasses B, vol. 49, no. 3, pp. 103-117, 2008.

[257] R. L. McGreevy, "Reverse Monte Carlo modelling," Journal of Physics Condensed Matter, vol. 13, no. 46, pp. R877-R913, 2001. 
[258] D. A. Keen and R. L. McGreevy, "Structural modelling of glasses using reverse Monte Carlo simulation," Nature, vol. 344 , no. 6265 , pp. 423-425, 1990.

[259] A. K. Soper, "Partial structure factors from disordered materials diffraction data: an approach using empirical potential structure refinement," Physical Review B, vol. 72, no. 10, pp. 1-12, 2005.

[260] J. K. Christie, M. Guthrie, C. A. Tulk et al., "Modeling the atomic structure of very high-density amorphous ice," Physical Review B, vol. 72, no. 22, Article ID 012201, 2005.

[261] Y. Kawakita, S. Tahara, H. Fujii, S. Kohara, and S. Takeda, "Comparison of partial structures of melts of superionic $\mathrm{AgI}$ and $\mathrm{CuI}$ and non-superionic AgCl," Journal of Physics Condensed Matter, vol. 19, no. 33, Article ID 335201, 2007.

[262] S. K. Mitra, "Molecular dynamics simulation of silicon dioxide glass," Philosophical Magazine B, vol. 45, no. 5, pp. 529-548, 1982.

[263] J. Sarnthein, A. Pasquarello, and R. Car, "Structural and electronic properties of liquid and amorphous $\mathrm{SiO}_{2}$ : an ab initio molecular dynamics study," Physical Review Letters, vol. 74, no. 23, pp. 4682-4685, 1995.

[264] D. C. Allan and M. P. Teter, "Nonlocal pseudopotentials in molecular-dynamical density-functional theory: application to $\mathrm{SiO}_{2}$," Physical Review Letters, vol. 59, no. 10, pp. 11361139, 1987.

[265] S. Kohara, K. Suzuya, H. Morita et al., "Relationship between topological order and glass forming ability in densely packed Enstatite and Forsterite composition glasses," Proceedings of the National Academy of Sciences, vol. 108, no. 36, Article ID 110469, p. 14780, 2011.

[266] B. Fultz, "Workshop on computational science 2010," Argonne National Laboratory, http://www.its.caltech.edu/ $\sim$ matsci/Publish/CompScatWkshp_2010.html. 

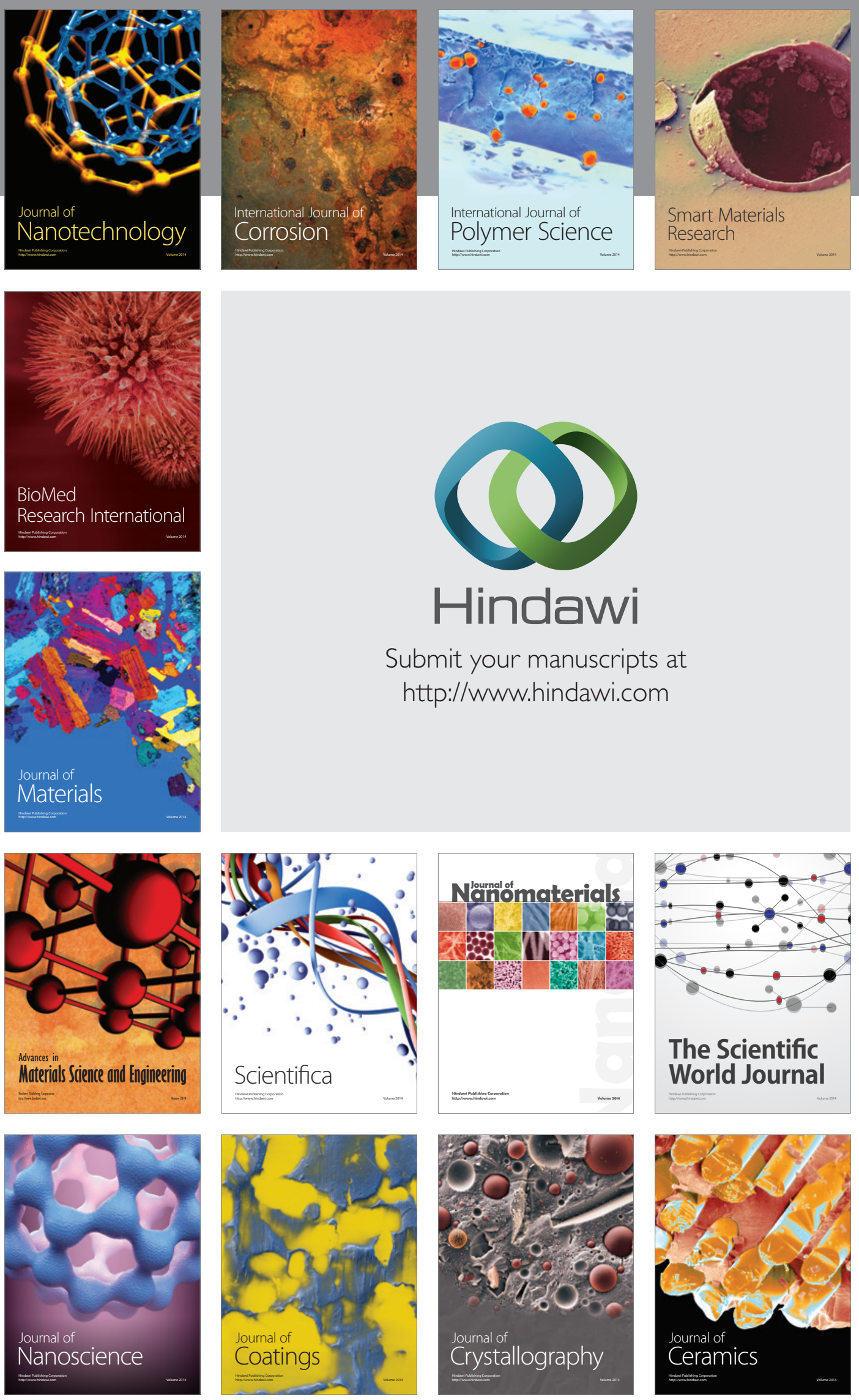

The Scientific World Journal

Submit your manuscripts at

http://www.hindawi.com

\section{World Journal}

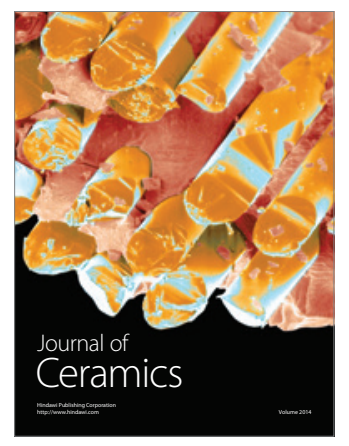

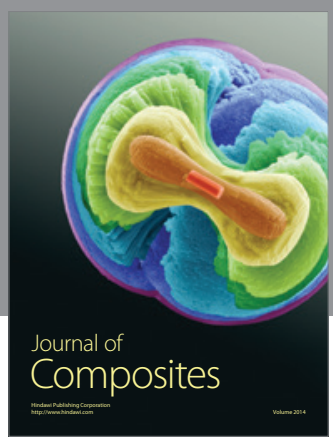
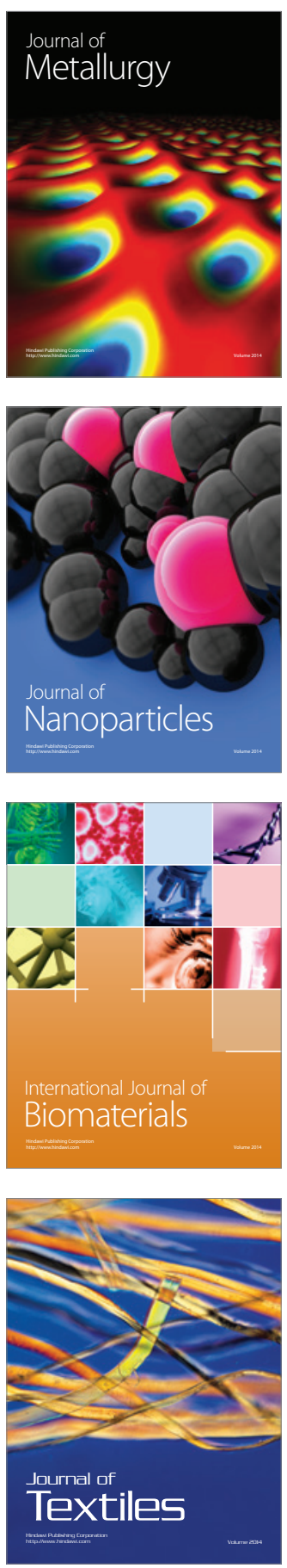